Aus der Abteilung Kardiologie und Pneumologie

(Prof. Dr. med. G. Hasenfuß)

im Zentrum Innere Medizin

der Medizinischen Fakultät der Universität Göttingen

\title{
Einfluss von Celecoxib auf die Entstehung und den Verlauf einer kardialen Hypertrophie
}

\author{
INAUGURAL-DISSERTATION \\ zur Erlangung des Doktorgrades \\ der Medizinischen Fakultät \\ der Georg-August-Universität zu Göttingen \\ vorgelegt von \\ Meike Grüber \\ aus Visp/ Schweiz
}

Göttingen 2010 
Dekan: Prof. Dr. med. C. Frömmel

I. Berichterstatter: Prof. Dr. med. G. Hasenfuß

II. Berichterstatter/in: Prof. Dr. med. A. El-Armouche III. Berichterstatter/in: Prof. Dr. med. M. Oppermann

Tag der mündlichen Prüfung: 29.03.2011 


\section{INHALTSVERZEICHNIS}

\section{EINLEITUNG}

1.1 Herzhypertrophie und -insuffizienz

Seite 8

$\begin{array}{ll}\text { 1.1.1 Definitionen } & \text { S. } 8\end{array}$

$\begin{array}{ll}\text { 1.1.2 Ursachen der Herzhypertrophie } & \text { S. } 8\end{array}$

1.1.3 Bedeutung der Herzhypertrophie S. 9

1.1.4 Physiologische versus pathologische Hypertrophie

1.2 Der Akt-Signalweg Seite 11

$\begin{array}{lll}\text { 1.2.1 Akt } & \text { S. } 11\end{array}$

$\begin{array}{lll}1.2 .2 \text { GSK-3 } \beta & \text { S. } 12\end{array}$

$\begin{array}{lll}1.2 .3 \text { mTor } & \text { S. } 13\end{array}$

1.2.4 Bedeutung des Akt-Signalweges für die Herzhypertrophie S. 13

1.3 Celecoxib und der Akt-Signalweg Seite 14

$\begin{array}{lll}\text { 1.3.1 Celecoxib } & \text { S. } 14\end{array}$

1.3.2 Celecoxib als Hemmer von Akt in Tumorzellen

1.4 Fragestellung dieser Arbeit Seite 16

2. MATERIAL UND METHODEN

2.1 Zellkultur Seite 17

2.1.1 Isolation von Kaninchenkardiomyozyten $\quad$ S. 17

2.1.2 Ausplattieren der Zellen $\quad$ S. 17

$\begin{array}{ll}\text { 2.1.3 Stimulation der Zellen } & \text { S. } 18\end{array}$

$\begin{array}{ll}\text { 2.1.4 Aufbereitung der Zellen } & \text { S. } 18\end{array}$

2.2 Western-Blot Seite 19

2.2.1 Zelllyse und Probenvorbereitung S. 19

2.2.2 Bestimmung der Proteinkonzentration $\quad$ S. 19

$\begin{array}{lll}\text { 2.2.3 Gel-Elektrophorese } & \text { S. } 20\end{array}$

$\begin{array}{lll}\text { 2.2.4 Protein- Transfer (Blotten) } & \text { S. } 20\end{array}$

2.3 Immun-Färbung Seite 21

2.4 Quantitative mRNA-Messungen Seite 22

2.4.1 RNA-Extraktion aus isolierten Kardiomyozyten $\quad$ S. 23

2.4.2 Erstellen der cDNA mittels Reverser Transkriptase S. 24

$\begin{array}{lll}2.4 .3 & \text { Real time PCR } & \text { S. } 24\end{array}$

$2.5\left[{ }^{3} \mathrm{H}\right]$-Leucin-Aufnahme-Messung Seite 25

2.6 In-vivo-Versuche Seite 25

2.6.1 Versuchsprotokoll $\quad$ S. 26

$\begin{array}{lll}\text { 2.6.2 Echokardiographie } & \text { S. } 26\end{array}$ 
2.6.3 Celecoxib-Therapie

S. 27

2.6.4 Konstriktion der transversalen Aorta (TAC)

S. 27

2.7 Statistische Auswertungen

Seite 28

2.8 Verwendete Materialien

Seite 28

\section{ERGEBNISSE}

3.1 Einfluss von Celecoxib auf den Akt-Signalweg

3.1.1 Effekt von Celecoxib auf Akt

Seite 35

3.1.2 Einfluss von Celecoxib auf GSK-3 $\beta$ und p70S6-Kinase

S. 37

3.2 Angriffspunkt für Celecoxib

3.2.1 Coxunabhängige Wirkung von Celecoxib

Seite 38

3.2.2 PTEN

S. 38

S. 39

3.3 Auswirkung auf indirekte Hypertrophie-Zeichen

3.3.1 Proteinsynthese

Seite 40

\subsubsection{BNP-Expression}

S. 41

S. 42

3.4 Einfluss auf SERCA-2A-Expression

3.5 In-vivo-Versuche

3.5.1 Auswirkung der Celecoxib-Behandlung auf Kontrolltiere

Seite 43

Seite 44

3.5.2 Einfluss der Celecoxib-Behandlung auf TAC Tiere

S. 45

S. 45

3.5.3 Auswirkungen auf die Sterblichkeit

S. 48

\section{DISKUSSION}

4.1 Rückblick auf die Fragestellungen der Arbeit

Seite 49

4.2 Akt und die Bedeutung der Herzhypertrophie

Seite 50

4.2.1 Adaptive versus maladaptive Hypertrophie

S. 50

4.2.2 Welche Bedeutung hat das Ausmaß der Akt-Aktivität

S. 51

4.3 Celecoxib als Therapieoption

Seite 53

4.3.1 Pharmakologische Modulationsmöglichkeiten

S. 53

4.3.2 Die Diskussion um selektive COX-2-Hemmer

S. 54

4.4 Zukunftsperspektiven

Seite 55

5. ZUSAMMENFASSUNG

S. 57

6. ANHANG: Abbildungsverzeichnis, Tabellenverzeichnis

S. 58

7. LITERATURVERZEICHNIS

S. 60 


\section{Abkürzungsverzeichnis}

ASS

ATP

BNP

COX

FS

GAPDH

GSK

HW/BW

IGF

Ins

IRS

LV

LVEDD

LVESD

MHC-Promotor

m-TOR

NFAT

NSAID

OD

PDGF

PDK-1

$\mathrm{PH}$-Domäne

PI3-Kinase

PP2A

Ptdlns(3,4,5)P3

PW

RV

Ser

SERCA-2A

SW

TAC

Thr
Acetylsalicylsäure

Adenosintriphosphat Brain-natriuretisches Peptid

Cyclooxygenase

Prozentuale Verkürzungsfraktion

Glycerinaldehyd-3-Phosphat-Dehydrogenase

Glykogen-Synthase-Kinase Herzgewicht-Körpergewicht-Quotient Insulinähnliche Wachstumsfaktoren Insulin Insulinrezeptorsubstrat Linker Ventrikel Linksventrikulärer enddiastolischer Durchmesser Linksventrikulärer endsystolischer Durchmesser Myosin-Schwerketten-Promotor mammalian target of rapamycin

Nuklearer Faktor der aktivierten T-Zellen Nicht-steroidale antiinflammatorische Wirkstoffe Optische Dichte Plättchen assoziierter Wachstumsfaktor Phosphoinositol-abhängige Proteinkinase 1 Pleckstrin-homologe Domäne Phosphoinositol-3-Kinase Protein-Phosphatase 2A Phosphatidylinositoltriphosphat posteriore Wand Rechter Ventrikel Serin sarkoplasmatische Calcium-ATPase Septumdicke transthorakale Aortenkonstriktion Threonin 


\section{EINLEITUNG}

\subsection{Herzhypertrophie und -insuffizienz}

\subsubsection{Definitionen}

Der Begriff Hypertrophie (griechisch: hyper: übermäßig, trophè: Ernährung) ist definiert als Vergrößerung von Geweben oder Organen durch Zunahme des Zellvolumens bei gleich bleibender Zellzahl. Im Gegensatz dazu steht die Hyperplasie (griechisch: hyper: übermäßig, plássein: bilden, gestalten), bei der die Vergrößerung des Organs durch eine vermehrte Zellzahl bedingt ist. Der Herzmuskel als stark ausdifferenziertes Gewebe reagiert auf dauerhaft erhöhte Belastung fast ausschließlich mit einer Hypertrophie (Kajsutra et al. 1998). Eine Hyperplasie beobachtet man nur bei den Bindegeweben im Herz, den Fibroblasten, die im Rahmen einer Herzinsuffizienz deutlich vermehrt vorkommen (Mann 1999; Manabe et al. 2002).

Die Herzinsuffizienz ist definiert als Unfähigkeit des Herzens, Blut und Sauerstoff in einem Maße zu den Organen zu transportieren, die den jeweiligen Bedürfnissen entspricht. Es resultieren die Krankheitssymptome Luftnot und schnelle Ermüdbarkeit (nach WHO-Definition von 1995).

\subsubsection{Ursachen der Herzhypertrophie}

Die Ursachen einer Herzhypertrophie sind sehr vielfältig. Generell kann bei den extrinsischen Auslösern zwischen einer vermehrten Druckbelastung (Nachlasterhöhung) oder einer Volumenbelastung (Vorlasterhöhung) unterschieden werden.

Einer der häufigsten Auslöser einer Hypertrophieantwort des Myokards ist der arterielle Hypertonus, wobei das Risiko, eine Herzhypertrophie zu entwickeln, mit der Höhe des Blutdruckes korreliert (Lip et al. 2000). Auf Grund der erhöhten Druckbelastung kommt es vorerst zu einer konzentrischen Hypertrophie des linken Ventrikels mit einer Verdickung der myokardialen Wände ohne signifikante Veränderung des Ventrikelvolumens. Auch im Rahmen einer Aortenstenose kommt es als Folge der Nachlasterhöhung zu einer konzentrischen Hypertrophie (Kupari et al. 2005). Insuffizienz-Vitien führen durch eine vermehrte Volumenbelastung zu einer exzentrischen Hypertrophie mit einer erweiterten Herzkammer und wenig verdickten Herzwänden. 
Nach einer ischämischen Schädigung von Herzmuskelgewebe im Rahmen eines Myokardinfarktes kommt es durch Umbauvorgänge zu einer kompensatorischen Hypertrophie des verbleibenden Myokards (Sutton et Sharpe 2000).

Im Gegensatz zu den oben beschriebenen extrinsischen Ursachen einer Hypertrophie stehen die so genannten intrinsischen Auslöser im Rahmen genetisch bedingter hypertropher Kardiomyopathien. Bis heute hat man eine Vielzahl von genetischen Veränderungen gefunden. besonders häufig betroffen sind hierbei die schweren Ketten des Myosins, das Myosinbindende Protein C oder das Troponin-T-Gen (Lim et al. 2001).

Auch ein erhöhtes Herzzeitvolumen im Rahmen eines exzessiven körperlichen Trainings (Pluim et al. 1999) oder bei gesunden Frauen in der Schwangerschaft (Mesa et al. 1999) spielt als Auslöser einer Hypertrophie eine Rolle.

\subsubsection{Bedeutung der Herzhypertrophie}

Lange war man der Meinung, dass eine Hypertrophie des Herzens als Reaktion auf eine erhöhte Belastung ein rein adaptiver Prozess sei. Eine Zunahme der Herzwanddicke führt laut dem Gesetz von Laplace ( $\mathrm{K}=\mathrm{P}$ x r / 2 d; K = Kraft pro Querschnitt der Wand; $P$ = Innendruck; $d$ = Wanddicke; $r$ = Radius) zum Ausgleich der steigenden Wandspannung. Man hielt die Hypertrophie für den Erhalt der Pumpfunktion des Herzens für notwendig (Hood et al. 1968; Grossman et al. 1975).

Ergebnisse neuerer Studien stellen dies jedoch in Frage: Setzt man transgen veränderte Tiere, deren Herzen die Fähigkeit zur Hypertrophie verloren haben, einer vermehrten Druckbelastung aus, so kommt es trotz fehlendem Ausgleich der Wandspannung nicht zu einer Einschränkung der Herzleistung (Esposito et al. 2002). Die Hypertrophie scheint also kein notwendiger Bestandteil einer adaptiven Reaktion auf vermehrte Belastung zu sein.

Bedeutung gewinnt diese Erkenntnis vor dem Hintergrund, dass das Auftreten einer Herzhypertrophie mit einer deutlich erhöhten Morbidität und einer bis zu fünffach erhöhten Mortalität assoziiert ist (Levy et al. 1990; Koren et al. 1991; Sullivan et al. 1993; Vakili et al. 2001). Entscheidend hierfür ist das Risiko einer sich entwickelnden Herzinsuffizienz. So findet man bei nahezu $70 \%$ aller Patienten mit Herzinsuffizienz echokardiographisch eine Hypertrophie des linken Ventrikels (Cowie et al.1999; Kupari et al. 2005). Eine Herzinsuffizienz ist assoziiert mit einer mittleren 5 Jahres-Überlebensrate von 59 \% (Mosterd et al. 2001). 
Auch das Auftreten von Herzrhythmusstörungen beobachtet man gehäuft bei Patienten mit einer linksventrikulären Hypertrophie. Das Risiko, an einem plötzlichen Herztod zu versterben, ist erhöht (McLenachan et al. 1987; Messerli et Grodzicki 1992).

\subsubsection{Physiologische versus pathologische Hypertrophie}

Nicht alle Auslöser der Hypertrophie gehen mit einem erhöhten Risiko für die Entstehung einer Herzinsuffizienz einher. Bei Leistungssportlern und Schwangeren kommt es durch das zunehmende Herzzeitvolumen ebenfalls zu einer Herzhypertrophie, die jedoch nicht mit einem erhöhten Risiko für die Entstehung einer Herzinsuffizienz assoziiert ist (Pluim et al. 1999, Eghbali et al. 2005). Man spricht in diesem Zusammenhang auch von einer physiologischen Herzhypertrophie im Gegensatz zur pathologischen Herzhypertrophie.

Neben den funktionellen Einschränkungen unterscheidet sich die pathologische Herzhypertrophie auch in anderen Merkmalen von einer physiologischen Herzhypertrophie, zum Beispiel in einer Veränderung des Genexpressionsmusters (Izumo et al. 1988). Ein typischer Marker der pathologischen Hypertrophie ist die ReExpression des fetalen Genproduktes BNP (Brain-natriuretisches Peptid). Während in gesunden Herzen kaum BNP nachweisbar ist (Yamamato et al., 1996), wird es bei pathologischer Überbelastung des Herzens (arterieller Hypertonus, Aortenstenose, etc.) in den Ventrikeln produziert. Schon nach $1 \mathrm{~h}$ steigt die Expression der BNP-m-RNA maximal an (Nakagawa et al. 1995). Die BNP-Konzentration im Blut korreliert mit der Herzbelastung und ist ein etablierter Marker zur Beurteilung der Schwere einer aus der Hypertrophie resultierenden Herzinsuffizienz (Jourdain et al. 2003; Lee et al. 2002). Bei Leistungssportlern ist trotz teilweise deutlicher Herzhypertrophie keine vermehrte BNP-Expression messbar (Almeida et al. 2002).

Auch histologisch betrachtet unterscheidet sich die pathologische von der physiologischen Hypertrophie. Das Vorkommen einer vermehrten Fibrose ist ein Zeichen einer pathologischen Herzhypertrophie, wohingegen es bei Sportlern nicht zu einer gesteigerten Ausbildung von Bindegeweben im Herzen kommt (McMullen et al. 2003). Eine gesteigerte Proteinsyntheserate und eine veränderte Organisation des Sarkomers sind allgemeine Zeichen und bei beiden Formen der Herzhypertrophie zu beobachten (Sugden et Fuller 1991). 
Es ist nicht endgültig geklärt, welche molekularen Mechanismen die Unterschiede zwischen physiologischer und pathologischer Hypertrophie bedingen. Während einige Autoren den beiden Hypertrophieformen unterschiedliche Signalwege zuschreiben (McMullen et al. 2003; Selvetella et al. 2004; Wilkins et al. 2004; DeBosch et al. 2006), wird heute vermehrt diskutiert, ob nicht die gleichen Signalwege in Abhängigkeit von der Aktivierungsintensität und -dauer an der Entstehung beider $\mathrm{Hy}$ pertrophieformen beteiligt sein könnten (Matsui et al. 2002; O'Neill et Abel 2005; Shiojima et al. 2005).

\subsection{Der Akt-Signalweg}

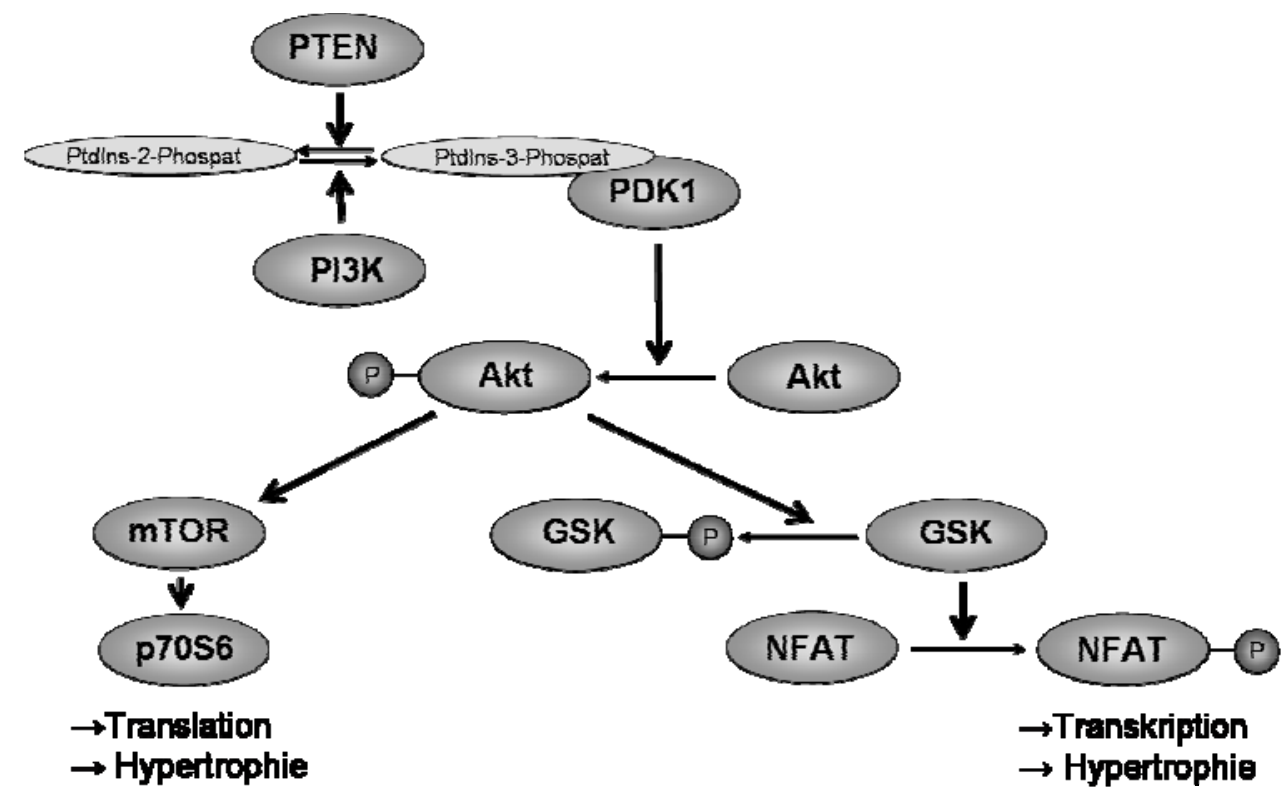

Abbildung 1.1 Überblick über den Akt-Signalweg, Erklärungen siehe im folgenden Text

Einen wichtigen Anteil an der Regulierung der Herzhypertrophie trägt der AktSignalweg, welcher bei der Regulation von Zellgröße, Stoffwechsel und Apoptose eine wichtige Rolle spielt (Frey et Olson 2003). Bekannte Stimulatoren dieser Kaskade sind Insulin, der insulinähnliche Wachstumsfaktor 1 (IGF-1) und Phenylephrin (Alessi et al. 1996). 


\subsubsection{Akt}

Akt ist eine Serin/Threonin-Kinase. Eine Phosphorylierung von Akt an $\mathrm{Thr}^{308}$ und $\mathrm{Ser}^{473}$ führt zur Aktivierung der Kinaseaktivität (Alessi et al. 1997). Die Phosphorylierung von Akt erfolgt durch die Phosphoinositol-abhängige Proteinkinase 1 (PDK-1) und kann nur in Anwesenheit von Phosphatydylinositoltriphosphat (Ptdlns $\left.(3,4,5) \mathrm{P}_{3}\right)$ stattfinden (Anderson 1998, Stephens et al. 1998). Das benötigte Ptdlns(3,4,5) $\mathrm{P}_{3}$ wird von der Phosphoinositol-3-Kinase (PI3-Kinase) aus seinen Vorstufen synthetisiert (Vanhaesebroeck et al. 1997). Eine Hemmung der PI3-Kinase verhindert eine Aktivierung der Akt durch die PDK-1 (Alessi et al. 1996).

Gegenspieler der PI3-Kinase bei der Regulation der Akt-Aktivität ist die Phosphatase PTEN. PTEN dephosphoryliert Ptdlns(3,4,5)P3 zu Phosphatidylinositoldiphosphat und antagonisiert dadurch die Wirkung der PI3-Kinase (Maehama et Dixon 1998). In ruhenden Zellen liegt PTEN in seiner dephosphorylierten, aktiven Form vor. Eine Phosphorylierung von PTEN inaktiviert die LipidphosphataseEigenschaften, führt somit zu einer erhöhten Ptdlns(3,4,5)P3-Konzentration und in der Folge zu einer vermehrten Akt-Aktivierung (Lu et al. 2003).

Zwei wichtige Zielsubstrate der Kinase Akt sind die Glykogen-Synthase-Kinase-3 $\beta$ (GSK-3ß) und das mammalian target of rapamycin (mTor) (Cross et al. 1995; Sekulic et al. 2000).

\subsubsection{GSK-3 $\beta$}

GSK-3 $\beta$ ist eine Serin/Threonin-Kinase. Ursprünglich wurde es als Schlüsselenzym im Glykogenstoffwechsel entdeckt, inzwischen ist GSK-3 $\beta$ als wichtiger Regulator verschiedener Zellfunktionen bekannt (Cohen et Frame 2001).

Anders als viele andere Kinasen liegt GSK-3 $\beta$ in ruhenden Zellen in aktiver dephosphorylierter Form vor. Eine Phosphorylierung an $\mathrm{Ser}^{9}$ durch Akt führt zur Inaktivierung von GSK-3 $\beta$ (Cross et al. 1995).

Ein wichtiges Zielsubstrat von GSK-3 $\beta$ ist der Nukleäre Faktor der aktivierten TZellen (NFAT). In seiner dephosphorylierten Form kann NFAT in den Zellkern transportiert werden, wo es als Transkriptionsfaktor eine Hypertrophie fördernde Wirkung entwickelt (Crabtree et Olson 2002). Unter anderem reguliert NFAT die vermehrte Transkription von BNP (Molkentin et al. 1998). 
GSK-3 $\beta$ phosphoryliert eine N-terminal gelegene regulatorische Domäne von NFAT, wodurch der Transport in den Zellkern und somit die Hypertrophie-Wirkung verhindert wird (Beals et al. 1997).

Eine vermehrte Akt-Aktivität führt also zu einer Herabsetzung der GSK-3ß-Aktivität und somit über eine erhöhte NFAT-Konzentration im Zellkern zur vermehrten Hypertrophie.

\subsection{3 mTor}

Ein weiteres relevantes Ziel von Akt ist mTor, eine Serin/Threonin-Kinase (Schmelzle et Hall 2000). Akt phosphoryliert mTOR an $\mathrm{Thr}^{2446}$ und $\mathrm{Ser}^{2448}$ und maskiert damit eine so genannte Repressordomäne. Es kommt zu einer verstärkten Proteinkinase Aktivität von mTor (Sekulic et al. 2000), was in der Folge eine vermehrte Translationsrate und gesteigerte Proteinsynthese auslöst (Wang et al. 2000).

Eine wichtige Rolle spielt hierbei die von mTor regulierte p70S6-Kinase. Eine Phosphorylierung der p70S6-Kinase an Thr389 durch mTor führt zur Aktivierung des Enzyms (Burnett et al. 1998). Durch die Phosphorylierung von S6, einer Komponente der 40S-Untereinheit der Ribosomen, führt die p70S6-Kinase zur vermehrten Stimulation der Initiierung und Elongation der Proteintranslation (Stewart et Thomas 1994).

Eine vermehrte Akt-Aktivität führt also über eine vermehrte mTor- und p70S6Aktivität zu einer Steigerung der Proteinbiosynthese.

\subsubsection{Bedeutung des Akt-Signalweges für die Herzhypertrophie}

Die Relevanz des Akt-Signalweges bei der Entwicklung der Herzhypertrophie lässt sich in verschiedenen Tierversuchen eindeutig darstellen. In hypertrophierten Herzen von Mäusen nach pathologischer Druckbelastung konnte eine deutlich gesteigerte Aktivität von Akt und p70S6-Kinase gemessen werden (Esposito et al. 2002; Shioi et al. 2003). Auch eine durch körperliches Training ausgelöste physiologische Hypertrophie geht mit einer gesteigerten Akt-Aktivität einher (McMullen et al. 2003). Weitere wichtige Informationen über die Bedeutung des Akt-Signalweges bei der Vermittlung einer Herzhypertrophie bieten diverse Studien mit transgen veränderten Tieren. Eine Überexpression von Akt führt schon nach etwa 2 Wochen zu einer deutlichen Erhöhung des Herzgewichtes (Matsui et al. 2002; Shioi et al. 2002; Shio- 
jima et al. 2005; Tanijama et al. 2005). Eine dauerhaft inaktive Form von Akt verhindert eine Hypertrophieantwort auf Druckbelastung (Esposito et al. 2002).

Auch eine veränderte Expression anderer Komponenten im Akt-Signalweg führen zu einer veränderten Hypertrophienantwort der Zellen. Eine vermehrte Aktivität der PI3-Kinase löst eine Herzhypertrophie aus (Shioi et al. 2000), ein Herabsetzen der PI3-Kinase-Aktivität in Kardiomyozyten führt zu einer verminderten Herzgröße unter Ruhebedingungen und einer abgeschwächten Hypertrophieantwort bei körperlichem Training (McMullen et al., 2003). Die Expression einer dauerhaft aktiven Form von GSK-3 $\beta$ in Mäusen reduziert die Hypertrophieantwort auf Druckbelastung und $\beta$ adrenerge Stimulation (Antos et al. 2002).

Nicht nur bei der Entstehung der Hypertrophie, sondern auch bei dem Übergang einer Hypertrophie in die Herzinsuffizienz scheint Akt eine Rolle zu spielen. So findet man in Gewebeproben aus humanen insuffizienten Herzen eine vermehrte Phosphorylierung von Akt und GSK-3 $\beta$ im Vergleich zu Kontrollproben (Haq et al. 2001).

Weitere Erkenntnisse würden Versuche mit einem pharmakologischen Hemmstoff von Akt bringen. Eine pharmakologische Hemmung von Akt in Kardiomyozyten in vivo ist bis heute jedoch nicht beschrieben.

\subsection{Celecoxib und der Akt-Signalweg}

\subsubsection{Celecoxib}

Celecoxib ist ein selektiver Hemmstoff der Cyclooxygenase-2 (COX-2). Pharmakologisch gehört Celecoxib in die große Gruppe der nicht-steroidalen antiinflammatorischen Wirkstoffe (NSAIDs). Auf Grund seiner analgetischen und antiinflammatorischen Eigenschaften wird Celecoxib zur Behandlung bei Reizzuständen degenerativer Gelenkerkrankungen und rheumatoider Arthritis eingesetzt. Üblich ist eine Dosierung von $200-400 \mathrm{mg}$ pro Tag.

Die COX ist ein in 2 Isoformen vorkommendes Enzym, welches die aus Phospholipiden der Zellmembran gespaltene Arachidonsäure zu Prostaglandinen und Thromboxan umsetzt (Dubois et al. 1998). Während die COX-1 nahezu ubiquitär vorkommt und besonders in der Magenmukosa, der Niere und in den Thrombozyten exprimiert wird (Crofford 1997), ist die Aktivität der COX-2 bei akuten oder chronischen Entzündungen und in Tumoren hochreguliert (Eberhart et al. 1994). 
Die Notwendigkeit einer Entwicklung von selektiven COX-2-Hemmern, wie Celeco$x i b$, ergab sich aus den gehäuft auftretenden gastrointestinalen Nebenwirkungen der unselektiven COX-Hemmer. Auf Grund einer verminderten Prostaglandinsynthese bei COX-1-Hemmung kommt es zu einer verminderten Produktion von protektivem Bikarbonat und Schleim der Magenmukosazellen (Wolfe et al. 1999). Es entstehen Erosionen oder Ulcera, aus denen es aufgrund der zusätzlich antithrombotischen Wirkung der COX-1-Hemmer, vermittelt über die Thromboxan-Aabhängige verminderte Thrombozytenaggregation, zu teilweise lebensbedrohlichen Blutungen kommen kann. Unter der Therapie mit selektiven COX-2-Hemmern treten diese gastrointestinalen Nebenwirkungen deutlich seltener auf (Bombardier et al. 2000).

\subsubsection{Celecoxib als Hemmer von Akt in Tumorzellen}

Schon länger bekannt ist ein Zusammenhang zwischen der regelmäßigen Einnahme von NSAIDs und der Inzidenz des Kolonkarzinoms (Kune et al. 1988; Baron et al. 2003), aber auch der Anzahl von Darm-Polypen bei familiärer Adenomatosis polyposis (Steinbach et al. 2000) und sporadisch auftretenden Darm-Polypen (Arber et al. 2006). Ein gemeinsamer Wirkmechanismus der verschiedenen eingesetzten NSAIDs ist die Hemmung der Cyclooxygenase, als Angriffspunkt für die antiproliferative Wirkung. Hsu et al. konnten jedoch zeigen, dass es speziell für Celecoxib neben den eventuell COX-abhängigen Wirkungen einen weiteren wichtigen antiproliferativ wirkenden Mechanismus gibt. An humanen Prostatakarzinomzellen konnte erstmalig gezeigt werden, dass Celecoxib Einfluss auf den Akt-Signalweg nehmen kann (Hsu et al. 2000). Auch in anderen Tumorgeweben konnte in der Folge gezeigt werden, dass die Rate an phosphoryliertem Akt durch den Einsatz von Celecoxib signifikant gesenkt werden konnte (Arico et al. 2002; Wu et al. 2004).

Im Jahre 2004 konnten Yang et al. zeigen, dass Celecoxib nicht nur in Tumorzellen, sondern auch in anderen Geweben die Phosphorylierung von Akt hemmen kann. Durch den Einsatz von Celecoxib konnte in vitro und in vivo die Proliferation von glatten Muskelzellen in Gefäßen gehemmt werden (Yang et al 2004). 


\subsection{Fragestellung dieser Arbeit}

Der Akt-Signalweg spielt eine bedeutende Rolle bei der Entstehung der Herzhypertrophie. Durch den Einsatz von Celecoxib lässt sich in verschiedenen Ausgangsgeweben die Akt-Aktivität hemmen.

Die Auswirkungen von Celecoxib auf den Akt-Signalweg in Kardiomyozyten und die Folgen einer möglichen Regulation sind noch nicht bekannt, sodass sich folgende Fragestellung ergibt:

1. Kann Celecoxib auch in Kardiomyozyten die Phosphorylierung von Akt regulieren?

2. Welche Auswirkungen hat diese Intervention auf die unterhalb von Akt gelegenen Signalwege?

3. Ist der Effekt von Celecoxib auf den Akt-Signalweg unabhängig von der COX?

4. Wie reguliert Celecoxib die Phosphorylierung von Akt?

5. Verändert eine Regulation des Akt-Signalweges in vitro die Hypertrophieantwort an isolierten Kardiomyozyten?

6. Welchen Einfluss hat Celecoxib auf die Ausbildung und den Verlauf einer Hypertrophie in vivo?

7. Wie wirkt es sich auf die Überlebensrate nach Druckbelastung aus? 


\section{MATERIAL UND METHODEN}

\section{$2.1 \quad$ Zellkultur}

\subsubsection{Isolation von Kaninchenkardiomyozyten}

Die Isolation ventrikulärer Kardiomyozyten erfolgt aus den Herzen weiblicher Chinchilla-Bastard-Kaninchen (1,5-2 kg). Die Tiere werden über eine Ohrvene heparinisiert und mit Thiopental Natrium (50mg/kg Körpergewicht) narkotisiert. Nach Aussetzen der Spontanatmung wird der Thorax eröffnet. Das Herz wird mit dem Aortenstumpf entnommen und in eisgekühlter Thyrode-Lösung gespült. Anschließend wird das Herz mit dem Aortenstumpf an einer Langendorff-Perfusionsapparatur fixiert und über 5-10 min mit Thyrode-Lösung retrograd perfundiert. Dabei soll das Herz kräftig und regelmäßig schlagen. Ein Wechsel auf kalziumfreie Thyrode-Lösung für 5 min führt zum Aussetzen der Kontraktion. Alle Lösungen müssen während des gesamten Vorgangs mit Sauerstoff begast werden.

Um die Herzmuskelzellen aus ihrem Verband zu lösen, wird das Herz durch Perfusion mit Kollagenaselösung über 10-20 min, abhängig von der Herzgröße, angedaut. Beginnt das Herz weich zu werden, wird die Verdauungsreaktion durch Zugabe der Stopp-Lösung beendet. Die Vorhöfe werden abgetrennt und die Ventrikel in der aufgefangenen Stopp-Lösung mit einer Schere zerteilt. Der Kolben mit der Zellsuspension wird bei $37^{\circ} \mathrm{C}$ etwa 20 min geschwenkt und danach mit einer $25 \mathrm{ml} \mathrm{Pi}$ pette mehrmals aufgezogen, um noch letzte Zellen zulösen. Die Zellsuspension wird durch Nylon-Gaze gefiltert und der Durchfluss mit der gleichen Menge Waschlösung verdünnt. Die Zellen werden in Thyrode-Lösung gewaschen. Der Kalziumgehalt der Waschlösungen wird langsam gesteigert bis eine Kalzium-Konzentration von 1,0 $\mathrm{mM}$ erreicht ist. Anschließend werden die Zellen in M199 Kulturmedium resuspendiert. Die Zellen werden bei $37^{\circ} \mathrm{C}$ und $5 \% \mathrm{CO} 2$ im Brutschrank gelagert.

\subsubsection{Ausplattieren der Zellen}

Die verwendeten 10-cm-Zellkulturschalen werden vor dem Einbringen der Zellen mit Laminin beschichtet, um ein Anheften der Myozyten am Boden zu erreichen und so folgende Waschschritte zu ermöglichen. Das Laminin wird mit Medium im Verhältnis 1:100 verdünnt. In jede 10-cm-Schale werden $3 \mathrm{ml}$ pipettiert und diese anschließend für 30 min in den Brutschrank gestellt. 
Die isolierten Kaninchenmyozyten werden für alle Versuche in einer Dichte von 500000 Zellen pro 10-cm-Schale in $5 \mathrm{ml}$ Medium ausgesät. Das überschüssige Medium aus dem Laminierungsprozess muss vorher absaugt werden. Nach 3-4 h Kultur im Brutschrank haben sich die Zellen am Boden angeheftet. Versuche mit einer Inkubationszeit von 24 h können jetzt gestartet werden. Bei Versuchen mit kürzeren Inkubationszeiten hat es sich als hilfreich erwiesen, die Schalen über Nacht ruhen zu lassen und erst am nächsten Tag mit der Stimulation zu beginnen, um nach dem Stress der Isolation wieder einen Ruhezustand der Zellen zu gewährleisten.

Sollen die Zellen über Nacht ruhen, erfolgt noch ein Mediumwechsel auf $10 \mathrm{ml}$ frisches Medium.

\subsubsection{Stimulation der Zellen}

Die Stimulation der Zellen erfolgt mit Insulin (10 $\mu \mathrm{mol} / \mathrm{l})$ oder Phenylephrin (10 $\mu \mathrm{mol} / \mathrm{l})$. Zusätzlich wird in den jeweiligen Gruppen Celecoxib in verschiedenen Konzentrationen eingesetzt $(0,10,25,30,50,70,100 \mu \mathrm{mol} / \mathrm{l})$. Das Celecoxib wird als Stocklösung in DMSO (Dimethylsulfoxid) angesetzt. Um einen Einfluss der jeweiligen Lösungsmittel auszuschließen, wird den Kontroll- und Insulingruppen jeweils die gleiche Menge der Lösungsmittel beigefügt. Je nach Versuchsaufbau verbleiben die Wirkstoffe in je $10 \mathrm{ml}$ Medium $1 \mathrm{~h}$ oder $24 \mathrm{~h}$ auf den Zellen.

\subsubsection{Aufbereitung der Zellen}

Die Versuchslösung wird abgesaugt und in jede Schale $5 \mathrm{ml}$ eisgekühltes PBS pipettiert. Die Zellen werden mit einem Zellschaber vom Boden der Schale gelöst und resuspendiert. Die PBS-Zell-Lösung wird in ein $10 \mathrm{ml}$ Zentrifugenröhrchen überführt. Der Vorgang wird mit $5 \mathrm{ml}$ PBS wiederholt. Die Zentrifugenröhrchen werden 5 min bei 3000 Umdrehungen bei $4^{\circ} \mathrm{C}$ zentrifugiert. Der klare Überstand wird abgesaugt und die zurückbleibenden Zellen in flüssigem Stickstoff eingefroren. Werden die Zellen nicht sofort weiterverarbeitet, können sie bei $-80^{\circ} \mathrm{C}$ gelagert werden. 


\subsection{Western-Blot}

\subsubsection{Zelllyse und Probenvorbereitung}

Um im Western Blot und der anschließenden Immunfärbung Proteine auftrennen und analysieren zu können, müssen die Zellen lysiert werden. Um die Proteine vor einem vorzeitigen Abbau zu schützen werden alle Versuchsschritte eisgekühlt durchgeführt. Zusätzlich ist der Lysepuffer mit Proteaseinhibitoren versetzt.

Jeder Zellansatz wird in $200 \mu$ Lysepuffer resuspendiert. Der Lysepuffer muss 30 min auf Eis einwirken. Danach wird die Zell-Lösung in ein 1,5-ml-Eppendorf-Cup überführt und zur mechanischen Unterstützung der Lyse fünfmal mit einer feinen Insulinspritze aufgezogen. Bei 8000 Umdrehungen werden die Proben 5 min bei $4^{\circ}$ C zentrifugiert. Der Überstand wird in ein neues 1,5-ml-Eppendorf-Cup überführt und das den Zelldebris enthaltende Pellet verworfen.

\subsubsection{Bestimmung der Proteinkonzentration}

Die Proteinkonzentrationsbestimmung erfolgt mit dem BCA-Proteinbestimmungs-Kit der Firma Pierce. Die Proteine bilden mit den in der Reaktionslösung vorgegebenen $\mathrm{Cu}^{2+}$-Ionen einen Komplex, wobei diese $\mathrm{zu} \mathrm{Cu}^{1+}$-Ionen reduziert werden. Die $\mathrm{Cu}^{1+}-$ Ionen bilden wiederum einen Komplex mit in der Lösung enthaltener Bicinchonininsäure (BCA). Es kommt zum Farbumschlag von Grün nach Violett, der photometrisch bestimmt wird.

Die Proben werden 1:20 mit doppelt destilliertem Wasser verdünnt. Je $25 \mu \mathrm{l}$ verdünnte Probe werden mit $200 \mu \mathrm{l}$ Reaktionslösung versetzt und $30 \mathrm{~min}$ bei $37^{\circ} \mathrm{C}$ leicht geschüttelt. Es wird in Dreifachbestimmung gearbeitet. Als Proteinstandard wird eine Albuminkonzentrationsreihe mit definierten Konzentrationen in Doppeltbestimmung mitgeführt. Alle Proben und Standards werden bei einer Wellenlänge von $562 \mathrm{~nm}$ im Photometer gemessen und die Proteinkonzentration an Hand der Standardkurve bestimmt.

Im Anschluss wird die Proteinkonzentration der später verwendeten Proben auf 1 $\mu \mathrm{g} / \mu \mathrm{l}$ durch Verdünnung mit dem Lysepuffer eingestellt und mit Laemmli-Puffer im Verhältnis 1:5 versetzt. Je $100 \mu \mathrm{l}$ der Proben werden vor der Verwendung 3,5 min bei $95^{\circ} \mathrm{C}$ erhitzt. Eine Ausnahme bilden hier die Proben, in denen SERCA-2A gemessen werden soll. Diese werden nicht erhitzt. 


\subsubsection{Gel-Elektrophorese}

Diese Methode ermöglicht das Auftrennen eines Proteingemisches nach der Molekülgröße. Die Proteine werden denaturiert und mit Natriumdodecylsulfat behandelt. Die Moleküle dieses Detergens sind negativ geladen. Sie legen sich an die aufzutrennenden Proteine und maskieren deren Eigenladung, so dass in der anschließenden Gel-Elektrophorese alle Proteine unabhängig von ihrer ursprünglichen Eigenladung zur Anode wandern. Die Geschwindigkeit und somit die erreichte Laufstrecke in einem als Molekülsieb dienenden Acrylamid-Gel sind allein von der Molekülgröße abhängig. Kleinere Proteine wandern schneller und damit weiter als größere.

Das hier verwendete Gelelektrophoresesystem nach Laemmli arbeitet mit einem Tris-Glycin Puffersystem. Die 0,7-1 mm dicken Gele werden in einem vertikalen Gelsystem gegossen. Ein $10 \%$ Trenngel wird mit einem 4\% Sammelgel überschichtet, ein eingesetzter Kamm bildet 10 Taschen, in die später die Proben aufgetragen werden. Ist das Sammelgel auspolymerisiert, werden die Gele mit den Glasplatten in eine Elektrodenapparatur eingespannt. Die innere und die äußere Laufkammer werden mit Laufpuffer befüllt, der Kamm entfernt und die Taschen vorsichtig mit je $25 \mu \mathrm{l}$ Probe (bzw $6 \mu \mathrm{l}$ bei der Bestimmung von SERCA-2A) befüllt. Zusätzlich werden $8 \mu \mathrm{l}$ eines Proteinmarkers pipettiert, der als Standard mitläuft und später das Zuordnen der einzelnen Banden ermöglicht. Bei 100 mA läuft das Gel etwa eine Stunde, bis der mit den kleinsten Molekülen laufende Laemmli-Puffer, als Blaufront sichtbar, gerade aus dem Gel heraus gelaufen ist.

\subsubsection{Protein-Transfer (Blotten)}

Die im Gel nach ihrer Molekülgröße aufgetrennten Proteine werden im nächsten Schritt auf eine Nitrozellulosemembran übertragen, da hier eine Anfärbung der Proteine mit Antikörpern möglich ist. Für den Protein-Transfer wird das Gel von den Glasscheiben getrennt und das Sammelgel abgeschnitten. Anschließend werden jeweils ein Kunststoffschwamm, 2 Lagen Filterpapier, die Nitrozellulosemembran, das Gel und wieder 2 Lagen Filterpapier und ein Kunststoffschwamm als „BlotSandwich“ aufeinander aufgebaut. Die Nitrozellulosemembran muss später anodenwärts liegen, da die Proteine im angelegten Spannungsfeld auf Grund der SDSBeladung wieder in Richtung Anode wandern. Alle Bestandteile müssen in Blockpuf- 
fer eingeweicht werden. Die "Sandwichs“ werden in eine Plastikkammer eingebracht, die mit Blockpuffer gefüllt wird. Unter Kühlung im Eisbad wird nun 2 mal $1 \mathrm{~h}$ mit $500 \mathrm{~mA}$ geblottet.

Die Proteine befinden sich anschließend auf der Nitrozellulosemembran und können zur Qualitätskontrolle mittels Ponceau-Färbung angefärbt werden. Die gefärbten Membranen werden fotographiert und anschließend in TBS-Puffer gewaschen.

Für die Immunfärbung werden die Membranen teilweise im Ponceau-gefärbten Zustand je nach Laufhöhe der gesuchten Proteine zerschnitten, um die Antikörperinkubation für die einzelnen zu untersuchenden Proteine zeitgleich durchführen zu können.

\subsection{Immun-Färbung}

Vor Beginn der Immunfärbungen müssen alle ungesättigten Bindungen der Nitrozellulosemembran geblockt werden. Hierzu wird die Membran über Nacht bei $4^{\circ} \mathrm{C}$ in 5 $\%$ Milchpuffer geschwenkt, alternativ $2 \mathrm{~h}$ bei Raumtemperatur. Vor dem Zugeben des ersten Antikörpers wird noch einmal mit TBS-Puffer gewaschen.

Die Membranen werden $2 \mathrm{~h}$ bei Raumtemperatur mit dem 1. Antikörper inkubiert (Ausnahme: GAPD $30 \mathrm{~min}$, Konzentrationen siehe Tabelle 2.1).

$\begin{array}{llll} & \text { Verdünnung } & \text { Lösungsmittel } & \text { Hersteller } \\ \text { GAPDH } & 1: 50000 & 0,5 \% \text { Milchpuffer } & \text { Bio Trend } \\ \text { P-Akt } & 1: 1000 & 0,5 \% \text { Milchpuffer } & \text { Cell Signaling } \\ \text { Akt } & 1: 1000 & 0,5 \% \text { Milchpuffer } & \text { Cell Signaling } \\ \text { P-GSK } & 1: 5000 & 0,5 \% \text { Milchpuffer } & \text { Cell Signaling } \\ \text { GSK } & 1: 2500 & 0,5 \% \text { Milchpuffer } & \text { BD Biosciences } \\ \text { P-p70S6 } & 1: 1000 & 0,5 \% \text { Milchpuffer } & \text { Cell Signaling } \\ \text { p70S6 } & 1: 1000 & 0,5 \% \text { Milchpuffer } & \text { Cell Signaling } \\ \text { SERCA2A } & 1: 20000 & 0,5 \% \text { Milchpuffer } & \text { ABR } \\ \text { P-PTEN } & 1: 1000 & 0,5 \% \text { Milchpuffer } & \text { Cell Signaling }\end{array}$

Tabelle 2.1 Konzentrationen 1. Antikörper für die Immunfärbung

Um ungebundene Antikörper zu entfernen, bevor der 2. Antikörper aufgetragen wird, werden die Membranen dreimal für $5 \mathrm{~min}$ in TBS-Puffer gewaschen, 
Die Membranen werden $1 \mathrm{~h}$ bei Raumtemperatur mit dem 2. Antikörper inkubiert (Konzentrationen siehe Tabelle 2.2).

$\begin{array}{llll}\text { 2. Antikörper } & \text { 1. Antikörper } & \text { Verdünnung } & \text { Lösungsmittel } \\ \text { Anti-Maus-IgG } & \text { GAPDH } & 1: 10000 & 0,5 \% \text { Milchpuffer } \\ \text { Anti-Kaninchen-IgG } & \text { P-Akt } & 1: 2000 & 0,5 \% \text { Milchpuffer } \\ \text { Anti-Kaninchen-IgG } & \text { Akt } & 1: 2000 & 0,5 \% \text { Milchpuffer } \\ \text { Anti-Kaninchen-IgG } & \text { P-GSK-3 } \beta & 1: 10000 & 0,5 \% \text { Milchpuffer } \\ \text { Anti-Maus-IgG } & \text { GSK-3 } \beta & 1: 5000 & 0,5 \% \text { Milchpuffer } \\ \text { Anti-Kaninchen-IgG } & \text { P-p70S6 } & 1: 2000 & 0,5 \% \text { Milchpuffer } \\ \text { Anti-Kaninchen-IgG } & \text { p70S6 } & 1: 2000 & 0,5 \% \text { Milchpuffer } \\ \text { Anti-Maus-IgG } & \text { SERCA2A } & 1: 10000 & 0,5 \% \text { Milchpuffer } \\ \text { Anti-Kaninchen-IgG } & \text { P-PTEN } & 1: 2000 & 0,5 \% \text { Milchpuffer }\end{array}$

Tabelle 2.2 Konzentrationen 2. Antikörper für Immunfärbung

Anschließend werden die Membranen erneut in TBS-Puffer dreimal für 10 min gewaschen. Die 2. Antikörper sind spezifisch gegen Maus- oder Kaninchen-IgG gerichtet und binden somit die in Maus oder Kaninchen produzierten 1. Antikörper. Zusätzlich ist an den 2. Antikörper eine Peroxidase gekoppelt. Die Membranen werden mit einem Chemolumineszenzsubstrat versetzt. Die Umsetzung des Substrates durch die antikörpergekoppelte Peroxidase führt zu einer Chemolumineszenzreaktion, die durch Auflegen von Filmen in der Dunkelkammer detektiert werden kann. Die Belichtungszeiten betragen je nach Antikörper und Verdünnung zwischen $5 \mathrm{~s}$ und $15 \mathrm{~min}$. Anschließend werden die Filme entwickelt und fixiert. Um die Intensität der erhaltenen Banden quantifizieren und vergleichen zu können, werden die Filme eingescannt und mit Hilfe des Alphalmager ${ }^{\circledR}$ HP (Alpha Innotech Corporation) densitometrisch ausgewertet.

\subsection{Quantitative m-RNA-Messungen}

Die real time PCR ist eine Methode, die es ermöglicht, die in einer PolymeraseKetten-Reaktion entstehenden Produkte in Echtzeit, beziehungsweise unmittelbar nach jedem Zyklus zu messen. Dies erfolgt mit Hilfe des Fluoreszenzfarbstoffes SYBR-Green der Firma Roche. Dieser Farbstoff bindet unspezifisch in der kleinen 
Furche von Doppelstrang-DNA. In dieser gebundenen Form fluoresziert SYBR Green bei gleicher Anregung wesentlich stärker als der freie Farbstoff. Die Intensität des Lichtsignals bei gleicher Menge Farbstoff ist also proportional zur Menge der vorliegenden Konzentration an Doppelstrang-DNA.

Trägt man die Stärke des gemessenen Signals gegen die Anzahl der bereits durchgeführten Zyklen auf, so erhält man eine Kurve, die die spezielle Kinetik der PCR wiedergibt. Zu Beginn ist das Signal einige Zyklen lang schwach mit nur sehr geringer Signalsteigerung, bis der Verlauf der Kurve in einen exponentielles Wachstum übergeht, wo mit jedem weiteren Zyklus eine deutliche Signalverstärkung sichtbar wird, um dann schließlich in einer Plateauphase zu enden. Der Übergang in die Plateauphase ist durch den Verbrauch der Edukte und einer Akkumulation der Produkte zu erklären. Die Zahl der benötigten Zyklen bis zum Beginn des exponentiellen Wachstums ist von der Anzahl der in der Ausgangslösung vorliegenden Kopienzahlen der zu messenden Nukleinsäure abhängig. Je mehr Kopien schon vorliegen, desto schneller wird ein exponentielles Wachstumsverhalten erreicht.

So ist es möglich, auf Grund der Reaktionskinetik im Vergleich zu Standardproben mit bekannter cDNA-Ausgangskonzentration auf die ursprünglich in der Versuchslösung vorhandene Kopienzahl rückzuschließen.

\subsubsection{RNA Extraktion aus isolierten Kardiomyozyten}

Die Myozyten werden isoliert, ausplattiert und anschließend mit Insulin und Celecoxib behandelt wie in den Abschnitten 2.1 bis 2.2.3 beschrieben. Das Ernten der Zellen erfolgt nicht mit PBS, sondern mit $175 \mu$ RNA-Lysepuffer. Die Zellösung wird in ein 1,5-ml-Eppendorf-Cup überführt.

Die anschließende Extraktion der gesamten RNA aus den isolierten Myozyten erfolgte mit Hilfe des SV total RNA Isolation-Kits (Promega, Madison, USA).

$350 \mu \mathrm{l}$ des RNA-Dilutions-Puffers werden zu der Zelllösung hinzu gegeben und gut vermischt. Nachdem die Lösung $3 \mathrm{~min}$ auf $70^{\circ} \mathrm{C}$ erhitzt wurde, wird $10 \mathrm{~min}$ bei 12000-14000 g zentrifugiert. Der Überstand wird abgenommen und in ein anderes Eppendorf-Cup überführt, mit $200 \mu \mathrm{l} 95 \%$ Ethanol versetzt und in das Körbchen eines Zentrifugenröhrchens transferiert, welches $1 \mathrm{~min}$ bei 12000-14000 g zentrifugiert wird. Die Flüssigkeit in dem Röhrchen wird verworfen, das Körbchen mit $600 \mu \mathrm{l}$ RNA-Wasch-Lösung befüllt und erneut $1 \mathrm{~min}$ bei $12000-14000 \mathrm{~g}$ zentrifugiert. 
Wieder wird das Röhrchen geleert und das Körbchen diesmal mit $50 \mu \mathrm{l}$ frisch angesetztem DNase-Inkubations-Mix befüllt. Nach 15 min Inkubation bei $20-25{ }^{\circ} \mathrm{C}$ wird $200 \mu \mathrm{l}$ DNase-Stop-Lösung dazugegeben und für $1 \mathrm{~min}$ bei 12000-14000g zentrifugiert.

Anschließend wird noch zweimal mit RNA-Wasch-Lösung gewaschen, wobei beim letzten Mal nur $250 \mu$ l RNA-Wasch-Lösung eingesetzt und 2 min zentrifugiert wird.

Zum Schluss wird der Deckel vom Körbchen entfernt und dieses in ein ElutionsRöhrchen geben. $100 \mu \mathrm{l}$ Nuclease-freies Wasser wird auf die Membran pipettiert, bei $12000-14000 \mathrm{~g}$ für 1 min zentrifugiert und anschließend das Körbchen entfernt.

Die im Röhrchen verbleibende Lösung enthält die gereinigte RNA.

\subsubsection{Erstellen der cDNA mittels Reverser Transkriptase}

Um die gewonnene RNA in die für die PCR benötigte DNA umzusetzen wird die Superscript III Reverse Transkriptase und Oligo(dT)-Primer eingesetzt.

$1 \mu \mathrm{l}$ der gewonnen RNA wird mit $1 \mu \mathrm{l}$ Oligo(dT)-Primern ( $50 \mu \mathrm{mol} / \mathrm{l}), 1 \mu \mathrm{dNTPs}(10$ $\mathrm{mmol} / \mathrm{l})$ und $11 \mu \mathrm{l}$ RNase -freiem Wasser gemischt, dann 5 Minuten auf $65^{\circ} \mathrm{C}$ erwärmt und anschließend 1 min auf Eis gelagert.

Es werden $4 \mu \mathrm{l}$ des 5xRT-Puffers, $1 \mu \mathrm{l}$ 0,1 DTT (mol/l) und 0,5 $\mu$ l Reverse Transkriptase Superscript III hinzugefügt und die Proben 5 Minuten auf $25^{\circ} \mathrm{C}$ und 50 Minuten auf $50^{\circ} \mathrm{C}$ erwärmt, anschließend wird 15 Minuten auf $70^{\circ} \mathrm{C}$ erhitzt, um die Transkriptase zu inaktivieren. Zum Schluss wird alles auf Eis gekühlt. Für die sich anschließende PCR werden die Proben mit $20 \mu \mathrm{l}$ Wasser verdünnt.

\subsubsection{Real time PCR}

Die real time PCR wird in einem LightCycler ${ }^{\circledR}$ (Roche Diagnostics) mit einem Probenvolumen von $20 \mu \mathrm{l}$ je Glaskapillare durchgeführt.

Jeder Reaktionsansatz beinhaltet: $2 \mu \mathrm{l}$ cDNA, je 0,5 $\mu \mathrm{l}$ der beiden Primer, $1 \mathrm{U}$ Taq DNA-Polymerase, $2 \mu \mathrm{l}$ 10xPCR Puffer, 0,2 mmol/l dNTP, $2,5 \mathrm{mmol} / / \mathrm{MgCl}_{2}, 500$ $\mathrm{mg} / \mathrm{BSA}, 50 \mathrm{ml} / \mathrm{I}$ DMSO und $1 \mu \mathrm{l}$ des $1 / 1000$ SYBR Green Stocks.

Nach einer Initialen Denaturierung bei $95^{\circ} \mathrm{C}$ über $30 \mathrm{~s}$ folgen 45 Zyklen mit einer Denaturierung bei $95^{\circ} \mathrm{C}$, einer Annealing-Phase bei $60^{\circ} \mathrm{C}$ für $5 \mathrm{~s}$ und der Elongationszeit von $10 \mathrm{~s}$ bei $72^{\circ} \mathrm{C}$. 
Die Emission wird jeden Zyklus bei $530 \mathrm{~nm}$ für BNP bei $82^{\circ} \mathrm{C}$ und für GAPDH bei $85^{\circ} \mathrm{C}$ gemessen.

Als Standards werden cDNA Lösungen mit bekannter Konzentration mitgeführt.

\section{$2.5\left[{ }^{3} H\right]$-Leucin-Aufnahme-Messung}

Mittels einer $\left[{ }^{3} \mathrm{H}\right]$-Leucin-Aufnahme-Messung ist es möglich, die Protein-SyntheseLeistung der Zellen anhand der eingebauten radioaktiv markierten Aminosäure Leucin zu messen. Eine erhöhte Proteinsyntheserate ist ein bekanntes Merkmal der kardialen Hypertrophie (Sudgen et Fuller 1991). Stellt eine Zelle vermehrt Proteine her, so benötigt sie hierfür verschiedene Aminosäurebausteine, die sie in der Zellkultur aus dem Nährmedium aufnimmt. Setzt man dem Nährmedium für die letzte Zeit der Inkubation radioaktiv markiertes Leucin zu, wird dieses von den Zellen aufgenommen und in die verschiedenen Proteine eingebaut. Die Menge des aufgenommenen radioaktiven Substrates ist anschließend messbar und korreliert mit dem Ausmaß der Proteinsyntheseleistung.

Isolierte Kaninchenmyozyten werden wie in 1.2 .1 beschrieben ausplattiert. Die Stimulation der Zellen erfolgt mittels Insulin (10 $\mu \mathrm{mol} / \mathrm{l})$ oder Phenylephrin (10 $\mu \mathrm{mol} / \mathrm{l})$. Zusätzlich wird ein Teil der Zellen mit Celecoxib $(10 \mu \mathrm{mol} / \mathrm{l})$ behandelt. Für die letzten $4 \mathrm{~h}$ einer 24 stündigen Inkubationszeit wird den Zellkulturen $5 \mu \mathrm{Ci} / \mathrm{ml}$ der radioaktiv markierten Aminosäure Leucin zugegeben. Nach Beendigung der Inkubationszeit werden die Zellen zweimal mit PBS gewaschen und 15 min auf Eis in $400 \mu$ Lysepuffer inkubiert. Anschließend werden die Zellen abgeschabt und in ein $2 \mathrm{ml}$ Eppendorf-Cup überführt. $250 \mu \mathrm{l}$ eiskalte Trichloressigsäure (20\%) wird für 15 min zugegeben, um die Proteine auszufällen. Nach 2 min Zentrifugation bei $14000 \mathrm{U} / \mathrm{min}$ wird der entstandene Überstand verworfen, das Pellet in $250 \mu \mathrm{l} 0,2 \mathrm{~N} \mathrm{NaOH}$ resuspendiert und $2 \mathrm{~min}$ bei $50^{\circ} \mathrm{C}$ im Thermomixer geschüttelt.

$1,5 \mathrm{ml}$ Szintillationscocktail wird zugegeben und die Radioaktivität in einem LiquidScintillation-Counter (Wallac 1409) gemessen.

\subsection{In-vivo-Versuche}

Um zu untersuchen, ob eine Celecoxibbehandlung auch in vivo Einfluss auf die Entstehung der Herzhypertrophie nehmen kann, wird ein entsprechender Tierversuch durchgeführt. Als etabliertes Verfahren zur Induktion einer Herzhypertrophie wird 
eine operative Einengung der transversalen Aorta gewählt. Die Behandlung der Tiere mit Celecoxib erfolgt über speziell präpariertes Futter.

Alle durchgeführten Versuche sind gemäß $\S 8$ Abs.1 Tierschutzgesetzes von der Bezirksregierung Braunschweig genehmigt (Aktenzeichen 509.42502/01-50.04 vom 11.10.2004). Für die Tierversuche werden weibliche C57BL/6-Mäuse verwendet, die zu Beginn der Untersuchung 22-25 g wiegen.

\subsubsection{Versuchsprotokoll}

Zu Beginn des Versuchsablaufs werden alle Tiere echokardiographisch untersucht. Es werden die Herzdimensionen (Wanddicke und Durchmesser der Herzhöhlen) und die Pumpfunktion bestimmt (Siehe auch Abschnitt 2.6.2). Danach wird die Therapie der Tiere mit Celecoxib oder Placebo über das Futter begonnen. 4 Tag nach Therapiebeginn werden die Mäuse operiert. Ein Teil der Tiere erhält eine operative Einengung der transversalen Aorta (TAC) wie in 2.6.4 beschrieben. Die anderen Mäuse werden ebenfalls einem operativen Eingriff unterzogen, bleiben jedoch ohne Konstriktion der Aorta (Sham-OP; Siehe auch Abschnitt 2.6.4). Hierdurch können unspezifische Effekte durch Narkose-, Wundheilungs- oder allgemeine Operationsnebenwirkungen ausgeschlossen werden. Tiere, die intraoperativ oder innerhalb der ersten $24 \mathrm{~h}$ postoperativ an den direkten Folgen der Operation, wie zum Beispiel zu starkem Blutverlust oder Pneumothorax, versterben, gehen nicht in die statistischen Auswertungen ein.

Jeweils 2 und 4 Wochen nach der Operation werden die Tiere erneut mittels Echokardiographie untersucht. Während des gesamten Versuchszeitraumes werden die Tiere regelmäßig klinisch beobachtet und gewogen, wobei besonders auf die Atmung, Bewegungsarmut und die Entstehung von Ödemen als Zeichen einer beginnenden Herzinsuffizienz geachtet wird. Bei einem Gewichtsverlust von mehr als $20 \%$ werden die Tiere mittels Genickbruch schmerzlos getötet.

\subsubsection{Echokardiographie}

Für die Echokardiographie werden die Tiere mit dem kurzwirksamen Avertin (1,2\%ige Verdünnung, $0,02 \mathrm{ml} / \mathrm{g}$ Körpergewicht) gewichtsadaptiert narkotisiert. Die Injektion des Avertins erfolgt intraperitonal. Die Tiere werden mit einem handelsüblichen Einmalrasierer an Brust und ventralem Hals rasiert. Um die Narkosetiefe ver- 
gleichbar zu gestalten, wird jeweils 10 min nach Injektion des Narkotikums mit der Untersuchung begonnen. Die Tiere werden für die Untersuchung in leichter Linksseitenlage fixiert. In einer zwei dimensionalen M-Mode Darstellung werden die kurze und die lange Achse eingestellt und der größte linksventrikuläre Durchmesser eingestellt. Die Septumdicke, die Dicke der Hinterwand, der endsystolische und enddiastolische Durchmesser des linken Ventrikels und Herzfrequenz werden gemessen. Die relative systolische Verkürzungsfraktion (fractional shortening) und die kalkulierte linksventrikuläre Masse werden aus den Angaben errechnet. Die Untersuchungen werden mit einem Schallkopf VS-VEVO 660/230 High Resolution Imaging System (VisualSonics Inc) durchgeführt. Bis die Tiere wieder bei Bewusstsein sind, werden sie von den anderen getrennt gehalten. Der Untersucher ist verblindet in Bezug auf die Gruppenzugehörigkeit der Tiere.

\subsubsection{Celecoxibtherapie}

Das Celecoxib wird den Tieren über die Nahrung zugeführt. Eine $25 \mathrm{~g}$ schwere Maus frisst unter Normalbedingungen konstant etwa $5 \mathrm{~g}$ Haltungsfutter pro Tag. Die Celecoxibkonzentration im Futter wird so gewählt, dass eine Tagesdosis von 50 $\mathrm{mg} / \mathrm{kg}$ Körpergewicht nicht unterschritten wird. Hierfür werden $400 \mathrm{~g}$ Haltungsfutter über Nacht in Wasser eingeweicht. Der entstandene Futterbrei wird mit dem Inhalt einer 200 mg Kapsel Celecoxib gut vermischt. Danach wird das Futter wieder portioniert und getrocknet, jedoch nie über $38^{\circ} \mathrm{C}$ erhitzt, da der Wirkstoff nicht hitzebeständig ist. Das Placebofutter wird ebenfalls in Wasser gelöst und neu geformt.

Dieses Futter und Wasser bekommen die Tiere ad libitum. Nach der ersten Echokardiographie und 4 Tage vor dem operativen Eingriff wird mit der Celecoxibfütterung begonnen.

\subsubsection{Konstriktion der transversalen Aorta (TAC)}

Am 4. Tag nach Beginn der Fütterung mit Celecoxib erfolgt der operative Eingriff. Die Mäuse werden mit einer Ketamin/Xylazin Narkose betäubt. Die Injektion erfolgt intraperitoneal. Anschließend werden die Tiere mit einer handelsüblichen Enthaarungscreme an Brust und ventralem Hals enthaart und die Augen durch Auftragen einer Augensalbe geschützt. Nach Kontrolle der Narkosetiefe mittels eines gezielten Schmerzreizes werden die Tiere in Rückenlage fixiert. Die Haut wird mit einem ca. 
1-1,5 cm langen Querschnitt oberhalb des Brustbeines eröffnet. Durch stumpfe Präparation der muskulären Strukturen wird die Luftröhre dargestellt und die Arteria carotis communis aufgesucht. Entlang dieser Leitstruktur wird der Aortenbogen dargestellt. Dazu ist es unter Umständen nötig, das OP-Gebiet durch einen kleinen Schnitt in das Manubrium sterni zu erweitern. Nach Erreichen des Aortenbogens wird dieser vorsichtig mobilisiert und ein chirurgischer Faden (6-0) mit Hilfe einer gebogenen Nadel unter der Aorta hindurch geführt. Eine auf der Aorta liegende stumpfe 27G- Kanüle dient beim Knoten zur Standardisierung des Stenosegrades Nach der Entfernung der Kanüle wird die Muskulatur des Halses mit einer Naht mittig adaptiert. Abschließend wird die Haut mit drei Einzelnähten geschlossen.

Bis zum Erwachen werden die Tiere auf einer Wärmeplatte von den übrigen Tieren getrennt gehalten. Die Tiere der Sham-Gruppe werden wie oben beschrieben narkotisiert und vorbereitet. Auch hier wird die Aorta mobilisiert und die gebogene Nadel unter der Aorta hindurchgeführt, der Aortendurchmesser wird jedoch anschließend nicht eingeengt, sondern die Wunde wie oben beschrieben wieder verschlossen.

Der Operateur ist verblindet in Bezug auf die Gruppenzugehörig der Tiere.

\subsection{Statistische Auswertungen}

Alle Daten werden als Mittelwerte \pm SEM angegeben. Die statistische Signifikanz der Unterschiede zwischen den Untersuchungsgruppen wurde mit Hilfe des gepaarten Student-t-Test ermittelt, wobei $p<0,05$ als statistisch signifikant angesehen wurde. Wenn Ergebnisse für mehrere Vergleiche herangezogen wurden, wurde ein Bonferroni-Korrektur durchgeführt ( $p<0,05 /$ Anzahl der Vergleiche). Zur Beurteilung der Überlebenskurven wurde eine Kaplan-Meier-Kurve erstellt und mittels Logrank-Test anlysiert.

\subsection{Verwendete Materialien}

\section{Lösungen für die Zellisolation}

\section{0xThyrodepuffer}

$\mathrm{NaCl}(137 \mathrm{mM})$

$80,06 \mathrm{~g}$

$\mathrm{KCl}(5,4 \mathrm{mM})$

$4,03 \mathrm{~g}$

$\mathrm{MgSO}_{4} \times 7 \mathrm{H}_{2} \mathrm{O}(1,2 \mathrm{mM})$

$2,96 \mathrm{~g}$

$\mathrm{Na}_{2} \mathrm{HPO}_{4} \times 12 \mathrm{H}_{2} \mathrm{O}(1,2 \mathrm{mM})$

$4,3 \mathrm{~g}$

HEPES (20 mM) 
1xThyrodepuffer ohne Kalzium

10xThyrodepuffer

$200 \mathrm{ml}$

Glucose $(2,7 \mathrm{~g} / \mathrm{l})$

$5,4 \mathrm{~g}$

100xPen/Strep

$20 \mathrm{ml}$

auf $1 \mathrm{l}$ mit $\mathrm{ddH}_{2} \mathrm{O}$ auffüllen

1xThyrodepuffer mit Kalzium

1xThyrodepuffer ohne Kalzium

$300 \mathrm{ml}$

$1 \mathrm{M} \mathrm{CaCl}_{2}$

$15 \mu \mathrm{l}$

Kollagenase-Lösung

1xThyrodepuffer ohne Calcium

$80 \mathrm{ml}$

Taurin

$600 \mathrm{mg}$

D,L-Glutaminsäure

$94 \mathrm{mg}$

D,L-Carnitin

$31 \mathrm{mg}$

Collagenase

$80 \mathrm{mg}$

Protease XIV

$3,2 \mathrm{mg}$

$1 \mathrm{M} \mathrm{CaCl}_{2}$

$2 \mu l$

Stopp-Lösung

1xThyrodepuffer ohne Kalzium

$300 \mathrm{ml}$

$1 \mathrm{M} \mathrm{CaCl}_{2}$

Albumin-Fraktion $\mathrm{V}$

BDM

$607 \mathrm{mg}$

\section{Lösungen für Zellkultur}

Medium M199 ready-to-use

M199-Medium (Sigma\#M7528)

$500 \mathrm{ml}$

Taurin

$312,5 \mathrm{mg}$

D,L-Carnitin

$500 \mathrm{mg}$

Creatin

$327,5 \mathrm{mg}$

100x Pen/Strep

$5 \mathrm{ml}$

100x L-Glutamin

$5 \mathrm{ml}$

Celecoxib Stock

Celecoxib

$200 \mathrm{mg}$

DMSO

Phenylephrin Stock

Phenylephrin

$10,37 \mathrm{mg}$

$\mathrm{ddH}_{2} \mathrm{O}$

$10 \mathrm{ml}$

Lyse-Puffer

IGEPAL CA-630

Glycerol

$100 \mu \mathrm{l}$ 
$\mathrm{NaCl}(1,37 \mathrm{M})$

Tris pH 7,4 (200 mM)

$\mathrm{NaF}(200 \mathrm{mM})$

Natrium orthovanadat (100 mM)

Natrium pyrophosphat (100 mM)

ß-Glycerolphosphat (500 mM)

EDTA pH 8,8 (100 mM)

EGTA pH 7,0 (10 mM)

Aprotonin $(10 \mathrm{mg} / \mathrm{ml})$

Leupeptin $(10 \mathrm{mg} / \mathrm{ml})$

Pepstatin A (0,5 mg/ml)

PMSF (200 mM)

$\mathrm{ddH}_{2} \mathrm{O}$

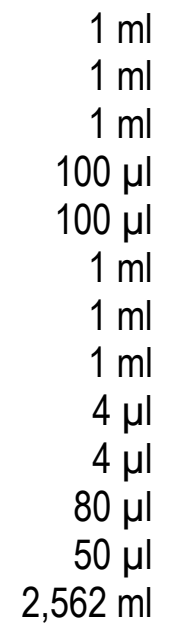

$1 \mathrm{ml}$

$1 \mathrm{ml}$

$1 \mathrm{ml}$

$100 \mu \mathrm{l}$

$100 \mu \mathrm{l}$

$1 \mathrm{ml}$

$1 \mathrm{ml}$

$1 \mathrm{ml}$

$4 \mu \mathrm{l}$

$4 \mu \mathrm{l}$

$80 \mu \mathrm{l}$

$50 \mu \mathrm{l}$

$2,562 \mathrm{ml}$

Lösungen für Western Blots

\section{Laemmli-Puffer}

Tris $\mathrm{HCl}$

$0,79 \mathrm{~g}$

SDS

$2 \mathrm{~g}$

$\mathrm{pH}$ mit $\mathrm{HCl} 37 \%$ auf 6,8 einstellen

Bromphenolblau

$\beta$-Mercapto-Ethanol

auf $18 \mathrm{ml} \mathrm{mit} \mathrm{H}_{2} \mathrm{O}$ auffüllen

$5 \mathrm{mg}$

$2 \mathrm{ml}$

10\% Trenn-Gel

$30 \%$ Acrylamid

$5 \mathrm{ml}$

4x Tris/SDS, pH 8,8

$3,75 \mathrm{ml}$

$\mathrm{H}_{2} \mathrm{O}$

$10 \%$ APS

$6,25 \mathrm{ml}$

$0,05 \mathrm{ml}$

$0,01 \mathrm{ml}$

4\% Sammel-Gel

$30 \%$ Acrylamid

4x Tris/SDS, pH 6,8

$0,67 \mathrm{ml}$

$1,25 \mathrm{ml}$

$3,08 \mathrm{ml}$

$0,03 \mathrm{ml}$

$10 \%$ APS

$0,01 \mathrm{ml}$

4x Tris/SDS, pH 8,8

Tris Base

$45,5 \mathrm{~g}$

SDS

$1 \mathrm{~g}$

pH mit $\mathrm{HCl} 37 \%$ auf 8,8 einstellen

auf $250 \mathrm{ml}$ mit $\mathrm{H}_{2} \mathrm{O}$ auffüllen

4x Tris/SDS, pH 6,8

Tris Base

$6,05 \mathrm{~g}$

$0,4 \mathrm{~g}$

$\mathrm{pH}$ mit $\mathrm{HCl} 37 \%$ auf 6,8 einstellen auffüllen 
5x Transfer-Puffer (ohne Methanol)

Tris Base

Glycine

$144 \mathrm{~g}$

$\mathrm{pH}$ mit $\mathrm{HCl} 37 \%$ auf 8,3 einstellen

mit $\mathrm{H}_{2} \mathrm{O}$ auf 2l auffüllen

1x Transfer-Puffer

5x Transfer-Puffer

$400 \mathrm{ml}$

Methanol

$400 \mathrm{ml}$

SDS $10 \%$

$2 \mathrm{ml}$

mit $\mathrm{H}_{2} \mathrm{O}$ auf $2 \mathrm{l}$ auffüllen

\section{5x SDS-Page Lauf-Puffer}

Tris Base

$30,2 \mathrm{~g}$

Glycine

SDS

$10 \mathrm{~g}$

pH mit $\mathrm{HCl} 37 \%$ auf 8,3 einstellen

mit $\mathrm{H}_{2} \mathrm{O}$ auf $2 \mathrm{l}$ auffüllen

1x SDS-Page Lauf-Puffer

$5 x$ SDS-Page Lauf-Puffer

$400 \mathrm{ml}$

mit $\mathrm{H}_{2} \mathrm{O}$ auf 2l auffüllen

\section{Lösungen für Immunfärbungen}

10x TBS Lösung

Tris Base

$48,4 \mathrm{~g}$

$\mathrm{NaCl}$

$58,48 \mathrm{~g}$

pH mit $\mathrm{HCl} 37 \%$ auf 7,5 einstellen

mit $\mathrm{H}_{2} \mathrm{O}$ auf $2 \mathrm{l}$ auffüllen

TBS-Tween Wasch-Puffer

10x TBS Lösung

$500 \mathrm{ml}$

Tween 20

\section{Lösungen für RNA-Extraktion}

RNA-Lyse-Puffer

RNA-Lyse-Puffer

$250 \mathrm{ml}$

Mercaptoethanol

DNase-Inkubations-Mix

Yellow core buffer

$\mathrm{MnCl}_{2}$

$40 \mu \mathrm{l}$

DNase Lösung

RNA-Wasch-Lösung

konzentrierte RNA-Wasch-Lösung

$177 \mathrm{ml}$

95\% Ethanol 


\section{DNase-Stop-Lösung}

konzentrierte DNase-Stop-Lösung

$26,5 \mathrm{ml}$

95\% Ethanol

$40 \mathrm{ml}$

\section{Chemikalien}

Chemikalien

100xPen/Strep

Acrylamid

Ammoniumpersulfat (APS)

Bromphenolblau

Butan-Dion-Monoxim (BDM)

Calciumchlorid $\left(\mathrm{CaCl}_{2}\right)$

Celecoxib

D,L-Carnitin

D,L-Glutaminsäure

Dimethylsulfoxid (DMSO)

Dinatriumhydrogenphosphat-Dodecahydrat

Entwickler

Ethanol

Ethylendiamintetraessigsäure (EDTA)

Ethylenglykoltetraessigsäure (EGTA)

Fixierer

Glukose

Glyzerol

$\mathrm{HCl}$

HEPES

IGEPAL CA-630

Insulin

Kaliumchlorid $(\mathrm{KCl})$

Kollagenase CLS 2

Laminin

L-Glutamin

M199-Medium

Magnesiumsulfat-Heptahydrat $\left(\mathrm{MgSO}_{4} \times 7 \mathrm{H}_{2} \mathrm{O}\right)$

Methanol

Natriumchlorid $(\mathrm{NaCl})$

Natriumdodecylsulfat (SDS)

Natriumfluorid ( $\mathrm{NaF}$ )

Natriumorthovanadat $\left(\mathrm{Na}_{3} \mathrm{PO}_{4}\right)$

Natriumpyrophosphat $\left(\mathrm{Na}_{4} \mathrm{P}_{2} \mathrm{O}_{7} \times 10 \mathrm{H}_{2} \mathrm{O}\right)$

PBS

Phenylephrin

Phenylmethansulfonylfluorid (PMSF)

Precision Plus Protein, All Blue Standarts

Protease XIV

Rinderalbumin

\section{Hersteller}

Sigma, Deisenhofen

Roth, Karlsruhe

Sigma, Deisenhofen

Bio Rad, München

Sigma, Deisenhofen

Sigma, Deisenhofen

Pfizer, Karlsruhe

Sigma, Deisenhofen

Sigma, Deisenhofen

Merck,Darmstadt

Merck,Darmstadt

Kodak, Paris, Frankreich

Merck,Darmstadt

Sigma, Deisenhofen

Sigma, Deisenhofen

Tetanal Photowerk

Merck,Darmstadt

Sigma, Deisenhofen Merck,Darmstadt

Sigma, Deisenhofen

Sigma, Deisenhofen

Aventis, Frankfurt

Merck,Darmstadt

Biochrom, Berlin

Sigma, Deisenhofen

Sigma, Deisenhofen

Sigma, Deisenhofen

Merck,Darmstadt

Merck,Darmstadt

Merck,Darmstadt

Bio Rad, München

Sigma, Deisenhofen

Sigma, Deisenhofen

Sigma, Deisenhofen Invitrogen, Karlsruhe Sigma, Deisenhofen Sigma, Deisenhofen

Bio Rad, München Sigma, Deisenhofen

Sigma, Deisenhofen 
ß-Glyzerolphosphat

SYBR Green Stock

Taurin

Tetramethylethylendiamin (TEMED)

Trichloressigsäure

Tris Base

Tween 20

$\beta$-Mercaptoethanol

Proteinaseinhibitoren

Proteaseinhibitoren

Pepstatin

Leupeptin

Aprotinin

Gebrauchsfertige Reaktionssysteme

Kit

Proteinbestimmungskit

Super script III reverse Transkriptase kit

SV total RNA isolation kit

Taq DNA Polymerase
Sigma, Deisenhofen

Roche, Mannheim

Sigma, Deisenhofen

Sigma, Deisenhofen

Merck, Darmstadt

Roth, Karlsruhe

Bio Rad, München

Sigma, Deisenhofen

Hersteller

Biomol, Hamburg

Biomol, Hamburg

Roche, Mannheim

\section{Primer für RT-PCR}

BNP: sense TGC TCT TCT TGC ACC TGT, antisense GCA GCT GCT GTA TCT CAG AAA;

GAPDH: sense TGC CGA GTA CGT GGT GGA AT, antisense ATG GCG TGC ACC GTG GTC AT

\section{Verwendete Radioaktivität}

\section{Radioaktivität}

L-[3,4,5-3H]-Leucin

Szintillisationscocktail Rotiszint eco plus

\section{Verbrauchsmaterialien}

Verbrauchsmaterialien

Filme

Nitrozellulosemembran Protran

Serologische Pipetten

Pipettenspitzen

Zellkulturschalen
Hersteller

PercinElmer, Boston, USA

Carl Roth, Karlsruhe

Hersteller

Fuji, Düsseldorf

Schleicher und Schuell, Dassel

Sarstedt, Newton, USA

Biozym, Oldenburg

Sarstedt, Newton, USA 
Zentrifugenröhrchen

E-cups $(0,5 \mathrm{ml}, 1 \mathrm{ml}, 2 \mathrm{ml})$

Zellschaber

\section{Geräte}

\section{Geräte}

Blotkammer

Brutschrank

Gefrierschrank $-86^{\circ} \mathrm{C}$

Gelelektrophoreseanlage

Light Cycler

Megafuge 2-OR

Multiimager

Photokammer

Photometer

Pipetten

Thermomixer 5436

Vortex Genie 2

Zentrifuge 5415R

Tiere

Chinchilla bastard Kaninchen C57bl6 Mäuse

\section{Narkotika}

Narkotika

Ketamin

Avertin

Xylazin
Sarstedt, Newton, USA

Eppendorf, Hamburg

Sarstedt, Newton, USA

Hersteller

Bio Rad, München

Heraeus Instruments, Berlin

Sanyo, München

Bio Rad, München

Roche, Mannheim, Deutschland

Heraeus Instruments, Berlin

Alphalnnotech Inc., San Leandro, USA

Siemens, Deutschland

BIO TEK Instruments $\mathrm{GmbH}$, Bad Friedrichshall

Eppendorf, Hamburg

Eppendorf, Hamburg

Bender + Hobein AG, Zürich, Schweiz

Eppendorf, Hamburg

Charles River Laboratories,Kisslegg

Charles River Laboratories,Kisslegg
Pfizer, Karlsruhe

Sigma, Deisenhofen

Sigma, Deisenhofen 


\title{
ERGEBNISSE
}

\section{ERGEBNISSE}

\subsection{Einfluss von Celecoxib auf den Akt-Signalweg}

\subsubsection{Effekt von Celecoxib auf Akt}

Um den Einfluss von Celecoxib auf den Akt-Signalweg in Herzmuskelzellen zu untersuchen, wurden isolierte Kardiomyozyten mit Insulin, einem bekannten Aktivator des Akt-Signalweges, stimuliert und gleichzeitig mit Celecoxib in unterschiedlichen Konzentrationen behandelt. Die Zellen wurden lysiert und die Proteine in einem Western-Blot-Verfahren aufgetrennt. Es wurde eine Immunfärbung mit spezifischen Antikörpern gegen Akt und seine Phospho-Form durchgeführt und die optischen Dichten der Western-Blot-Banden als Maß für die Expression von Akt bzw. von phosphoryliertem Akt densitometrisch ausgewertet.
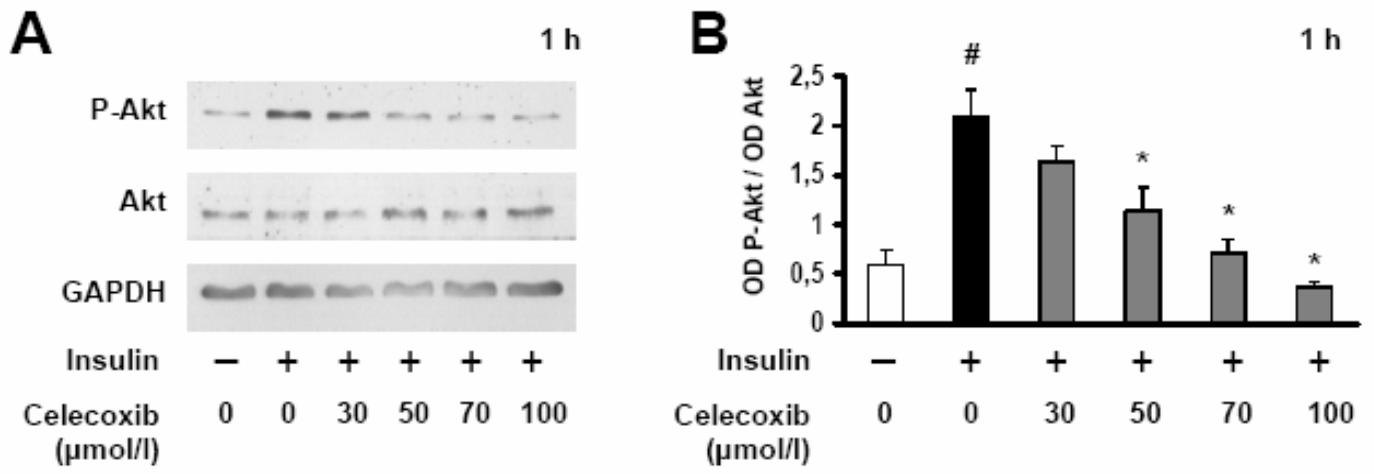

\begin{abstract}
Abbildung 3.1 Konzentrationsabhängiger Effekt von Celecoxib auf die Phosphorylierung von Akt (Inkubationszeit $1 \mathrm{~h}$ );

A Repräsentativer Western-Blot: isolierte Kaninchenmyozyten wurden mit (+) und ohne (-) Insulin und mit Celecoxib in aufsteigender Konzentration (0-100 $\mu \mathrm{mol} / \mathrm{l}) 1 \mathrm{~h}$ behandelt. Die Myozyten-Lysate wurden im Western-Blot-Verfahren analysiert und anschließend mit spezifischen Antikörpern für Akt und seine Phosphoform (P-Akt) inkubiert;

B statistische Auswertung von 8 Experimenten. Gemessen wurden die optischen Dichten (OD) der Western-Blot-Banden, \# vs Kontrolle $p<0,0002$; * vs Insulin $p<0,04$
\end{abstract}

Eine Stimulation der Kardiomyozyten mit Insulin führte nach $1 \mathrm{~h}$ zu einer signifikanten Erhöhung des Anteils an phosphoryliertem Akt (ODP-Akt/ODAkt: Insulin: $2,08 \pm 0,28$ vs Kontrolle: $0,60 \pm 0,15 ; n=8, p<0,0002$; Abb. 3.1). In Anwesenheit von 
Celecoxib $(50 \mu \mathrm{mol} / \mathrm{l})$ wurde die insulinbedingte Zunahme der Phosphorylierung von Akt signifikant gehemmt (ODP-Akt/ODAkt: Ins+Cel50: 1,14 $\pm 0,24$ vs Insulin: 2,08 $\pm 0,28 ; n=8, p<0,002 ;$ Abb. 3.1).

Durch den Einsatz höherer Celecoxibkonzentrationen $(100 \mu \mathrm{mol} / \mathrm{l})$ konnte die insulinbedingte Zunahme der Phosphorylierung von Akt vollständig aufgehoben werden (Abb. 3.1).

Durch eine Verlängerung der Inkubationszeit (24 h) konnte bereits eine deutlich geringere Celecoxibkonzentration $(10 \mu \mathrm{mol} / \mathrm{l})$ die insulinbedingte vermehrte Phosphorylierung von Akt signifikant senken (ODP-Akt/ODAkt: Ins+Cel10: 0,95 $\pm 0,14$ vs Insulin: $1,99 \pm 0,14 ; n=4, p<0,01 ; A b b .3 .2)$.

A

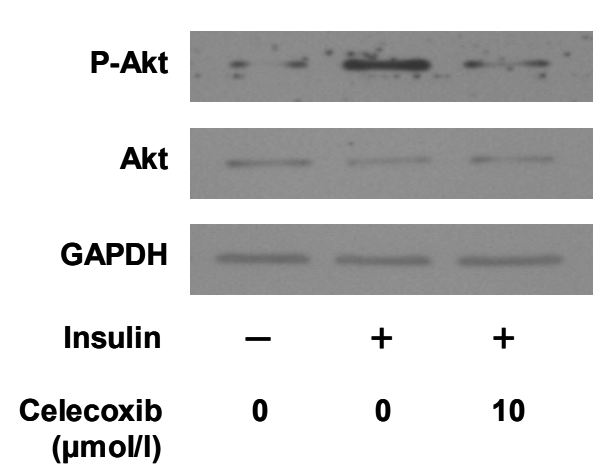

B

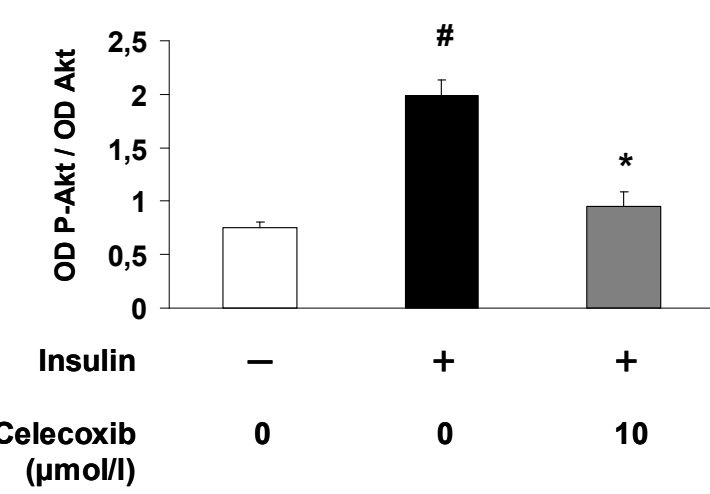

Abbildung 3.2 Zeitabhängiger Effekt von Celecoxib auf die Phosphorylierung von Akt (Inkubationszeit 24 h);

A Repräsentativer Western-Blot: isolierte Kaninchenmyozyten wurden mit (+) und ohne (-) Insulin und mit Celecoxib (10 $\mu \mathrm{mol})$ behandelt. Die Myozyten-Lysate wurden im WesternBlot-Verfahren analysiert und anschließend mit spezifischen Antikörpern für Akt und seine Phosphoform (P-Akt) inkubiert;

B Statistische Auswertung von 4 Experimenten. Gemessen wurden die optischen Dichten (OD) der Western-Blot-Banden, \# vs Kontrolle $p<0,007 ;{ }^{*}$ vs Insulin $p<0,006$

Um auszuschließen, dass es sich bei den an Kaninchenmyozyten gesehen Effekten um eine artspezifische Besonderheit handelt, führten wir exemplarische Versuche mit isolierten Myozyten von Mäusen durch.

Die Behandlung der Zellen mit Insulin (30 min) erhöhte die Rate an phosphoryliertem Akt (ODP-Akt/ODAkt: Kontrolle: 5,79 $\pm 0,71$ vs Insulin: 7,89 $\pm 3,3 ; n=2$ ). Eine zeit- 
gleiche Behandlung der Zellen mit Celecoxib (10 $\mu \mathrm{mol} / \mathrm{l})$ führte auch bei den Mausmyozyten zu einer deutlich geringeren Zunahme der insulinbedingt vermehrten AktPhosphorylierung (ODP-Akt/ODAkt: Ins+Cel10: 4,14 $\pm 0,28$ vs Insulin: 7,89 $\pm 3,3 ; n=2$ ). Diese Ergebnisse zeigen, dass Celecoxib in Herzmuskelzellen die Phosphorylierung von Akt hemmt. Dieser Effekt ist zeit- und konzentrationsabhängig.

\subsubsection{Einfluss von Celecoxib auf GSK-3 $\beta$ und p70S6-Kinase}

Wichtige Zielsubstrate von Akt sind GSK-3 $\beta$ und die p70S6-Kinase. Um einen Effekt auch auf GSK-3 $\beta$ und die p70S6-Kinase nachzuweisen, wurden Kaninchenmyozyten mit Insulin und Celecoxib behandelt, ein Western-Blot durchgeführt und in der anschließenden Immunfärbung spezifische Antikörper gegen GSK-3 $\beta$ und p70S6Kinase und die jeweiligen phosphorylierten Formen eingesetzt und die optischen Dichten der Western-Blot-Banden als Maß für die Expression densitometrisch bestimmt.

Die Stimulation der Zellen mit Insulin über $1 \mathrm{~h}$ steigerte den Anteil an phosphorylier-

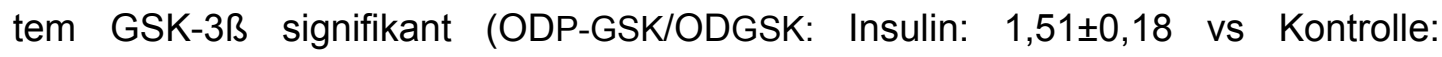
$0,56 \pm 0,10 ; n=8, p<0,0002$; Abb. 3.3). Auch die Rate an phosphorylierter p70S6Kinase stieg nach der Behandlung mit Insulin signifikant an (ODP-p70S6/ODp70S6: Insulin: 1,27 $\pm 0,07$ vs Kontrolle: 0,84 $\pm 0,06 ; n=5, p<0,02 ;$ Abb. 3.3).

Eine zeitgleiche Behandlung mit Celecoxib (50 $\mu \mathrm{mol} / \mathrm{l})$ führte zu einer signifikant geringer ausgeprägten Steigerung der insulinbedingt erhöhten Rate an phosphoryliertem GSK-3ß (ODP-GSK/ODGSK: Ins+Cel50: $0,83 \pm 0,10$ vs Insulin: $1,51 \pm 0,18$; $\mathrm{n}=8, \quad \mathrm{p}<0,005 ; \quad$ Abb. 3.3) und p70S6-Kinase (ODP-p70S6/ODp70S6: Ins+Cel50: $0,88 \pm 0,10$ vs Insulin: 1,27 $\pm 0,07 ; n=5, p<0,02 ;$ Abb. 3.3). In Anwesenheit von 100 $\mu \mathrm{mol} / \mathrm{l}$ Celecoxib wurde die insulinbedingte Zunahme der Phosphorylierung von GSK-3 $\beta$ vollständig gehemmt (Abb. 3.3).

Die Auswirkungen der Celecoxib bedingten Hemmung von Akt lassen sich auch in den nachgeschalteten Signalwegen nachweisen. Die reduzierte Akt-Aktivität führte zu einer verminderten Phosphorylierung von p70S6-Kinase und GSK-3 $\beta$. 
A

$1 \mathrm{~h}$

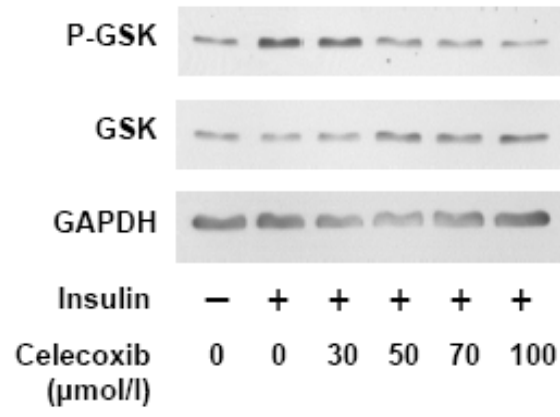

C

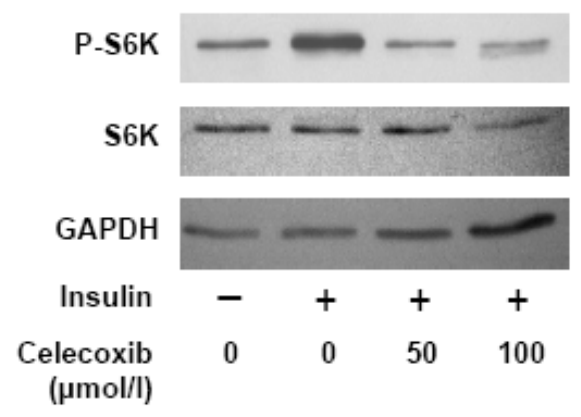

B

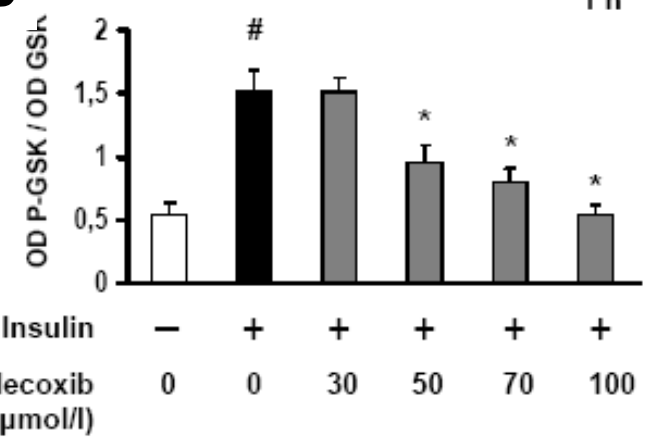

D

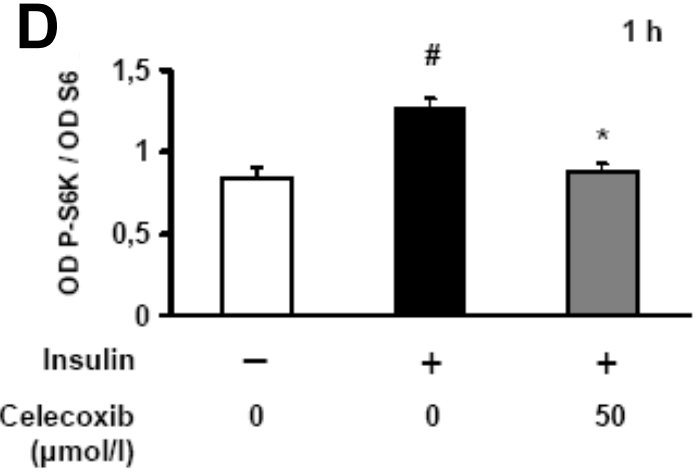

Abbildung 3.3 Konzentrationabhängiger Effekt von Celecoxib auf die Phosphorylierung von GSK-3 $\beta$ und p70S6-Kinase (Inkubationszeit $1 \mathrm{~h}$ );

A+C Repräsentative Western-Blots: isolierte Kaninchenmyozyten wurden mit (+) und ohne () Insulin und mit Celecoxib in aufsteigender Konzentration (0-100 $\mu \mathrm{mol} / \mathrm{l})$ inkubiert. Die Myozytenlysate wurden im Western-Blot-Verfahren aufgetrennt und anschließend mit spezifischen Antikörpern für GSK-3 $\beta$, p70S6-Kinase und seine Phosphoform (P-GSK-3 $\beta$, P-S6K) behandelt;

B statistische Auswertung von 8 Experimenten, gemessen wurden die optischen Dichten (OD) der Western-Blot-Banden, \# vs Kontrolle $p<0,0002$; * vs Insulin $p<0,002$; D Statistische Auswertung von 5 Experimenten, gemessen wurden die optischen Dichten (OD) der Western-Blot-Banden, \# vs Kontrolle $p<0,02 ;{ }^{*}$ vs Insulin $p<0,02$

\subsection{Angriffspunkt für Celecoxib}

\subsubsection{COX-unabhängige Wirkung von Celecoxib}

Um zu untersuchen, ob die Effekte von Celecoxib auf den Akt-Signalweg abhängig von der COX-Hemmung der Substanz sind, wurde alternativ Acetylsalicylsäure (ASS) als etablierter Hemmstoff der COX eingesetzt.

Isolierte Kardiomyozyten wurden mit Insulin stimuliert (1 h) und gleichzeitig mit ASS in unterschiedlichen Konzentrationen (50 $\mu \mathrm{mol} / \mathrm{l}, 100 \mu \mathrm{mol} / \mathrm{l})$ behandelt. 
Die Stimulation mit Insulin über $1 \mathrm{~h}$ führte zu der bekannten Zunahme der AktPhosphorylierung. Im Gegensatz zu Celecoxib konnte ASS die insulinbedingte vermehrte Phosphorylierung von Akt nicht hemmen (ODP-Akt/ODAkt: Ins+ASS50: 1,079 vs Insulin: 1,102; n=4; ODP-Akt/ODAkt: Ins+ASS100: 1,088 vs Insulin: 1,102; $\mathrm{n}=4$; Abb. 3.4).

Acetylsalicylsäure als typischer Vertreter der COX-Hemmer hatte im Gegensatz zu Celecoxib keinen Einfluss auf die Phosphorylierung von Akt, so dass die Wirkung von Celecoxib auf den Akt-Signalweg als COX unabhängig gewertet werden kann.

A

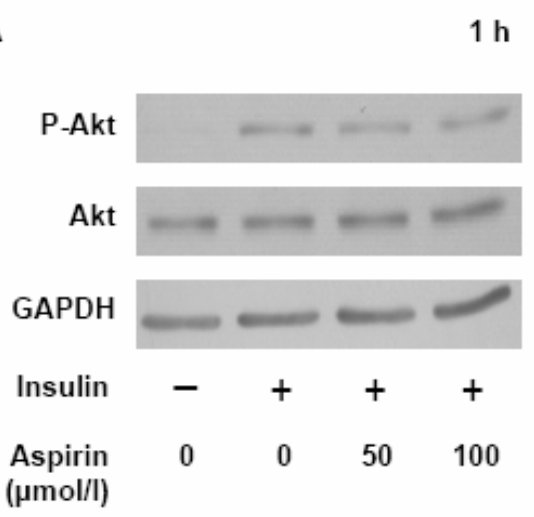

B

$1 \mathrm{~h}$

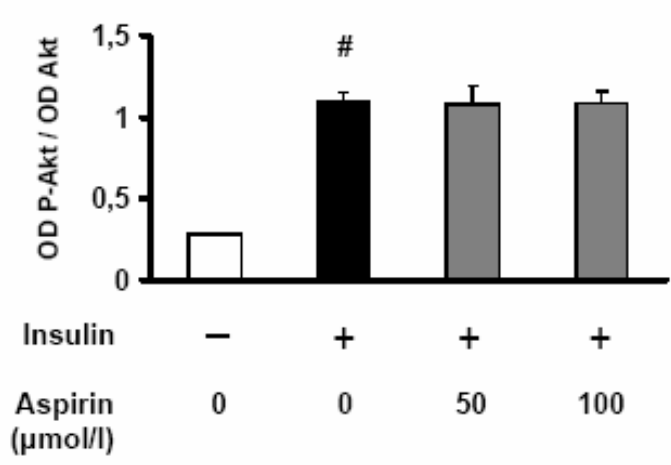

Abb. 3.4 Wirkung von ASS auf die Phosphorylierung der Akt (Inkubationszeit 1 h); A Repräsentativer Western-Blot: isolierte Kaninchenmyozyten wurden mit (+) und ohne (-) Insulin und mit ASS in aufsteigender Konzentration (0-100 $\mu \mathrm{mol} / \mathrm{l}) \mathrm{h}$ behandelt. Die Myozyten-Lysate wurden im Western-Blot-Verfahren analysiert und anschließend mit spezifischen Antikörpern für Akt und seine Phosphoform (P-Akt) inkubiert; B statistische Auswertung von 4 Experimenten. Gemessen wurden die optischen Dichten (OD) der Western-Blot-Banden

\subsubsection{PTEN}

Um den Mechanismus zu klären, über den Celecoxib die Phosphorylierung von Akt hemmt, untersuchten wir oberhalb von Akt gelegene Elemente der Signalkaskade.

Eine wichtige Rolle bei der Regulation der Akt-Aktivität spielt die Phosphatase PTEN. Damit Akt phosphoryliert und aktiviert werden kann, ist Ptdlns $(3,4,5) \mathrm{P}_{3}$ notwendig, welches von der PI3-Kinase bereitgestellt wird. PTEN, als Gegenspieler der PI3-Kinase, dephosphoryliert Ptdlns $(3,4,5) \mathrm{P}_{3}$, so dass dieses nicht mehr für die Phosphorylierung von Akt zur Verfügung steht. Eine vermehrte Aktivität der PTEN könnte eine verminderte Phosphorylierung von Akt erklären. Die dephosphorylierte Form von PTEN ist aktiv, die phosphorylierte Form ist inaktiv (Oudit et al. 2004). 
Um die Auswirkungen einer Celecoxibbehandlung auf PTEN zu untersuchen, wurden isolierte Kaninchenmyozyten wieder mit Insulin und Celecoxib in verschiedenen Konzentrationen behandelt.

Durch die Celecoxibbehandlung ließ sich die Rate an phosphoryliertem PTEN signifikant hemmen (ODP-PTEN/ODGAPDH: Ins+Cel50: 0,86 $\pm 0,11$ vs Insulin: $1,15 \pm 0,09$; $n=5, p<0,005 ;$ Abb. 3.5).

Die Tatsache, dass Celecoxib zu einer vermehrten Dephoshorylierung der PTEN und damit zu einer vermehrten PTEN Aktivität führte, weist darauf hin, dass die beschriebenen Einflüsse von Celecoxib auf den Akt-Signalweg über eine Regulation der PTEN-Aktivität bedingt sind.
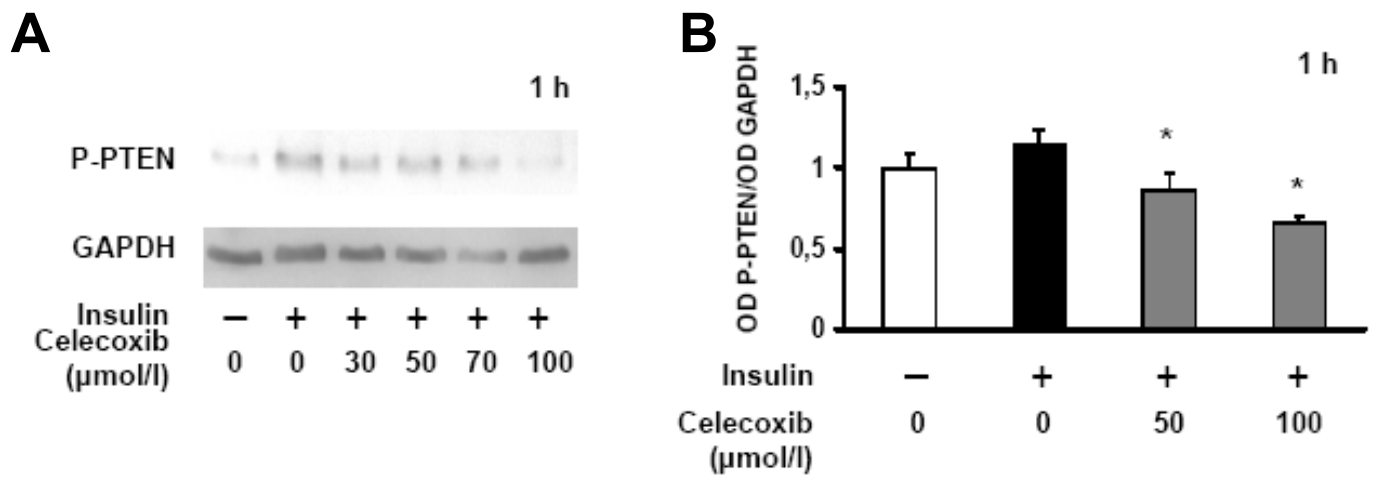

Abbildung 3.5 Konzentrationsabhängiger Effekt von Celecoxib auf die Phosphorylierung von PTEN (Inkubationszeit $1 \mathrm{~h}$ );

A exemplarischer Western-Blot: isolierte Kaninchenmyozyten wurden mit (+) und ohne (-) Insulin und mit Celecoxib in aufsteigender Konzentration (0-100 $\mu \mathrm{mol} / \mathrm{l}) 1 \mathrm{~h}$ inkubiert, die Myozytenlysate wurden im Western-Blot-Verfahren analysiert und anschließend mit spezifischen Antikörpern für die Phospho-Form der PTEN (P-PTEN) angefärbt;

B statistische Auswertung von fünf Experimenten, gemessen wurden die optischen Dichten (OD) der Western-Blot-Banden, * vs Insulin $p<0,005$

\subsection{Auswirkung auf indirekte Hypertrophiezeichen}

Der Akt-Signalweg spielt eine wichtige Rolle bei der Entstehung der Herzhypertrophie (Hardt et Sadoshima 2002). Nachdem wir zeigen konnten, dass die Behandlung von Myozyten mit Celecoxib hemmende Wirkung auf den Akt-Signalweg hat, untersuchten wir, ob diese Regulation auf zellulärer Ebene Auswirkungen auf die Hypertrophieantwort der Myozyten hat. Hierzu wurden die Expression des fetalen 
Genproduktes BNP und die Proteinsyntheseleistung der Zellen als indirekte Hypertrophiezeichen gemessen.

\subsubsection{Proteinsynthese}

Ein Surrogatparameter der kardialen Hypertrophie ist das Maß der Proteinsyntheserate. Hypertrophierende Zellen zeigen eine gesteigerte Proteinsynthese (Sugden et Fuller 1991).

Isolierte Kaninchenmyozyten wurden mit Insulin stimuliert (24 h). Für die letzen $4 \mathrm{~h}$ wurde radioaktiv markiertes Leucin ins Nährmedium der Zellen gegeben. Die Zellen nehmen Aminosäuren aus dem Nährmedium auf und setzen diese in der Proteinsynthese um. Die aufgenommene Menge an radioaktiven Aminosäuren ist proportional zur Syntheseleistung der Zelle.

A

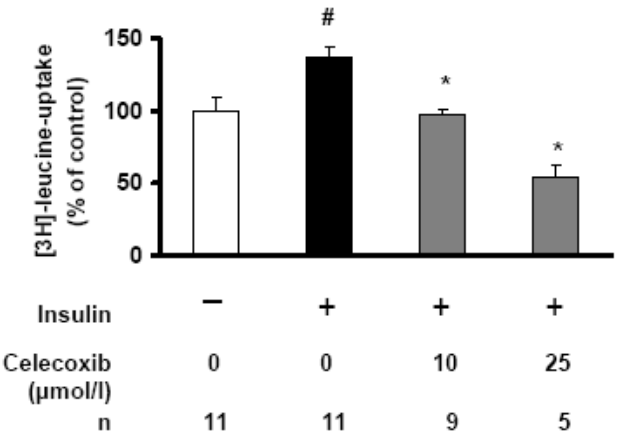

B



Abbildung 3.6 Auswirkung einer Celecoxibbehandlung auf die Proteinsyntheseleistung (Inkubationszeit 24 h); isolierte Kaninchenmyozyten wurden ohne (-) und mit Insulin $(+)$ oder Phenylephrin (+) und mit Celecoxib verschiedener Konzentrationen $(0,10,25 \mu \mathrm{mol} / \mathrm{l})$ behandelt, die Proteinsyntheseleistung mittels [3H]-Leucin Aufnahme Messung analysiert, statistische Auswertung der Experimente;

A Insulin als Stimulator des Akt-Signalweges; \# vs Kontrolle $p<0,0004,{ }^{*}$ vs Insulin $p<0,01$; B Phenylephrin als Stimulator des Akt-Signalweges; \# vs Kontrolle $p<0,0004,{ }^{*}$ vs Insulin $p<0,01$

Die Stimulation der Zellen mit Insulin führte zu einer Steigerung der Proteinsynthese um 36.9 $\pm 7.3 \%$ ( $n=11, p<0,0004$; Abb. 3.6). Eine Behandlung der Zellen mit Pheny- 
lephrin, einem alternativen Stimulator des Akt-Signalweges, steigerte die Syntheserate um $26.2 \pm 6.9 \%(n=12, p<0,001)$.

Durch eine Behandlung der Zellen mit Celecoxib (10 oder $25 \mu \mathrm{mol} / \mathrm{l}$ ) konnte der Effekt der Insulin- und Phenylephrin-Stimulation auf die Proteinsyntheserate vollständig gehemmt werden $(n=9, p<0.0005$ vs Insulin; $n=10, p<0.0001$ vs Phenylephrin; Abb. 3.6).

\subsubsection{BNP-Expression}

Ein weiteres Merkmal hypertrophierender Myozyten ist die Reexpression fetaler Genprodukte (Izumo et al. 1988), wie zum Beispiel das Brain natriuretische Peptid (BNP). Während in gesunden Herzen kaum BNP nachweisbar ist, wird es bei pathologischer Überbelastung in den Ventrikeln exprimiert (Yamamato et al. 1996).

Um die Auswirkungen einer Celecoxibbehandlung auf die Expression von BNP zu messen, wurden isolierte Kaninchenmyozyten mit Insulin stimuliert und gleichzeitig mit Celecoxib behandelt. Die Zellen wurden lysiert und in einem real-time PCR Verfahren analysiert. Gemessen wurde der BNP/GAPDH m-RNA Quotient als Maß für die BNP m-RNA Expression.

Die Inkubation isolierter Kaninchenmyozyten mit Insulin (24 h) führte zu einer deutlich vermehrten mRNA-Expression von BNP (BNP/GAPDH: Kontrolle: 0,039 $\pm 0,002$ vs Insulin: 0,051 $\pm 0,003 ; n=6, p<0,01 ; A b b .3 .7)$.

Eine Behandlung der Zellen mit Celecoxib (25 $\mu \mathrm{mol} / \mathrm{l})$ konnte die insulinbedingte Zunahme der BNP Expression vollständig hemmen (Abb. 3.7).

Durch eine Behandlung mit Celecoxib ist sowohl die Proteinsyntheseleistung als auch die Reexpression von BNP als Reaktion auf hypertrophe Stimuli beeinflussbar. Somit konnten wir zeigen, dass Celecoxib Auswirkungen auf Merkmale der kardialen Hypertrophie hat. 


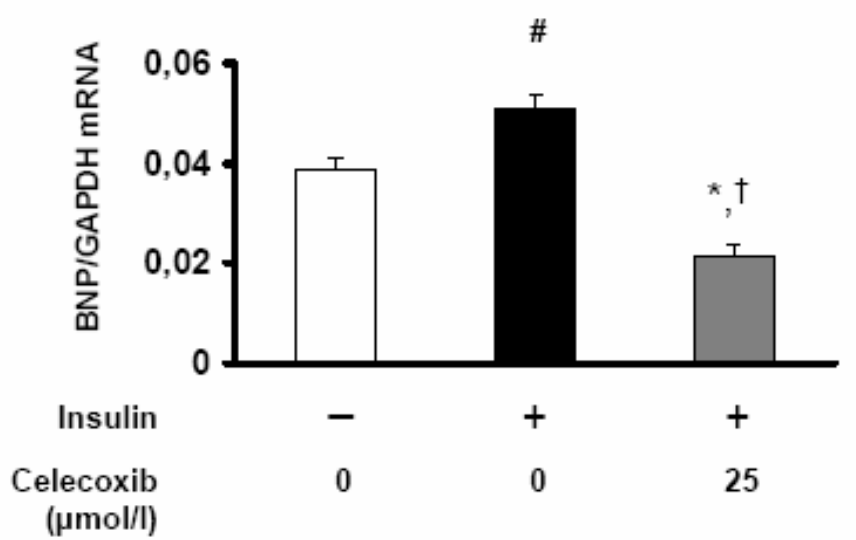

\begin{abstract}
Abbildung 3.7 Auswirkung einer Celecoxibbehandlung auf die BNP-m-RNAExpression (Inkubationszeit $24 \mathbf{~ h}$ ); isolierte Kaninchenmyozyten wurden mit (+) und ohne (-) Insulin und mit $25 \mu \mathrm{mol} / \mathrm{I}(25)$ und ohne (0) Celecoxib behandelt, anschließend quantitative BNP mRNA Bestimmung per real time PCR normalisiert gegen GAPDH; Statistische Auswertung von 6 Experimenten; \# vs Kontrolle $p<0,006$; * vs Insulin $p<0,0002$; † vs Kontrolle $p<0,007$
\end{abstract}

\title{
3.4. Einfluss auf SERCA-2A-Expression
}

In transgen veränderten Tieren, die kardial eine dauerhafte GSK-3 $\beta$ Aktivität aufweisen, beobachtet man eine herabgesetzte Expression des Kalziumtransporters SERCA-2A und eine deutlich eingeschränkte Relaxationsfähigkeit der Kardiomyozyten (Michael et al. 2004). Auch in humanen insuffizienten Herzen konnte eine Runterregulation der SERCA-2A nachgewiesen werden (Hasenfuss 1998). Durch die Celecoxibbehandlung in vitro kam es ebenfalls zu einer vermehrten Aktivität der GSK-3 $\beta$, so dass wir die Auswirkungen der Celecoxibbehandlung auf die Expression der SERCA-2A untersuchten.

Isolierte Kaninchenmyozyten wurden mit Insulin und Celecoxib $(25 \mu \mathrm{mol} / \mathrm{l})$ behandelt $(24 \mathrm{~h})$. Die Zellen wurden lysiert und mittels eines Western-Blot-Verfahrens aufgetrennt. In der anschließenden Immunfärbung wurden spezifische Antikörper gegen SERCA-2A eingesetzt.

Nach $24 \mathrm{~h}$ Inkubation konnte keine Veränderung in der SERCA-2A Expression festgestellt werden, weder durch die Insulinstimulation (ODSERCA/ODGAPDH: Insulin: 3,23 vs Kontrolle: 3,34; $n=4 ;$ Abb. 3.8) noch durch eine Celecoxibbehandlung (ODSERCA/ODGAPDH: Ins+Cel25: 3,09 vs Insulin: 3,07; n=4; Abb. 3.8). 
Eine mäßige Regulation der GSK-3 $\beta$, wie sie mittels Celecoxib erreicht wurde führte nicht zu einer Veränderten Expression der SERCA-2A.

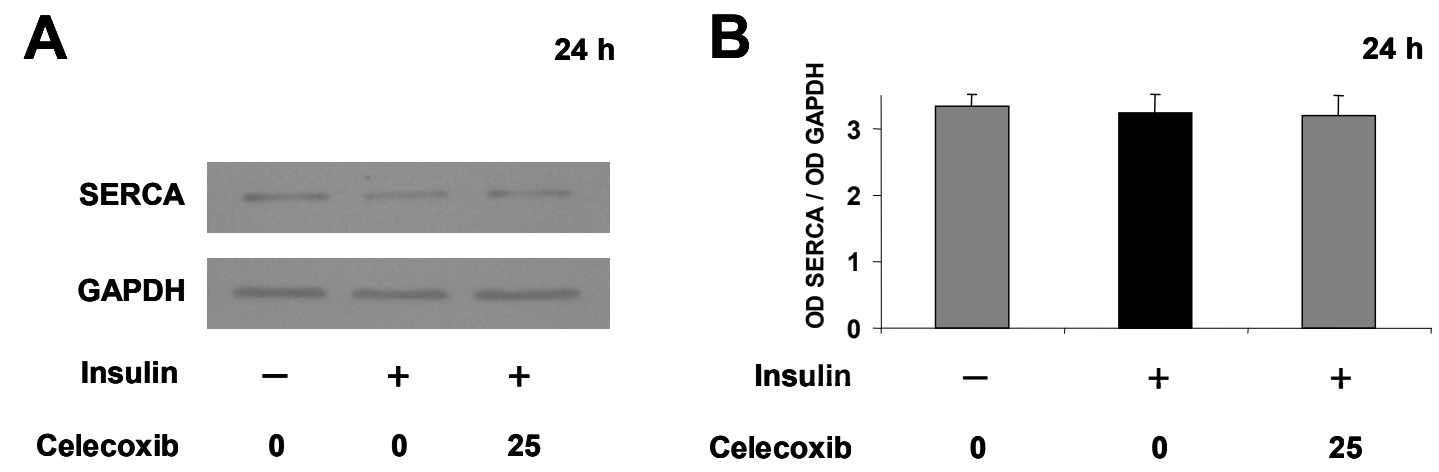

\begin{abstract}
Abbildung 3.8 Einfluss von Celecoxib auf die Expression der SERCA-2A (Inkubationszeit 24);

A Repräsentativer Western-Blot: isolierte Kaninchenmyozyten wurden mit (+) oder ohne (-) Insulin und mit Celecoxib $(25 \mu \mathrm{mol} / \mathrm{l}) 24 \mathrm{~h}$ inkubiert; Die Myozytenlysate wurden im WesternBlot-Verfahren analysiert und anschließend mit spezifischen Antikörpern für SERCA behandelt;

B Statistische Auswertung von 4 Experimenten; Gemessen wurden die optischen Dichten (OD) der Western-Blot-Banden
\end{abstract}

\title{
3.5. In-vivo-Versuche
}

Nachdem wir zeigen konnten, dass Celecoxib in vitro die Phosphorylierung von Akt und den untergeordneten Signalwegen regulieren kann und dadurch antihypertroph wirkt, untersuchten wir im folgenden den Effekt dieser Regulation auf die Entstehung und den Verlauf einer Herzhypertrophie im Tiermodel.

Als etabliertes Verfahren zur Induktion einer Hypertrophie wählten wir eine operative Einengung der transversalen Aorta (TAC). Durch diese künstlich erzeugte Aortenstenose kommt es zu einer deutlich gesteigerten Druckbelastung des linken Herzens und zu einer vermehrten Herzarbeit. Die Tiere einer Kontrollgruppe wurden ebenfalls einer Operation unterzogen, blieben jedoch ohne Einengung der Aorta (Sham). 
Bereits 3 Tage vor dem jeweiligen operativen Eingriff und während des gesamten Versuchablaufes wurde die Hälfte der Tiere über das Futter mit Celecoxib behandelt, die anderen Tiere erhielten Placebo-Futter.

\subsubsection{Auswirkungen der Celecoxib-Behandlung auf Kontrolltiere}

Zunächst untersuchten wir den Einfluss der Celecoxibbehandlung auf die Kontrolltiere. Nach zwei Wochen konnten keine signifikanten Veränderungen in Bezug auf die Dimensionen der Herzhöhlen oder die Kontraktilität des linken Ventrikels zwischen den mit Celecoxib behandelten und den mit Placebo behandelten Kontrolltiere gemessen werden (LVEDD: Sham/Celecoxib $(n=15): 3,69 \mathrm{~mm}$ vs Sham/Placebo $(n=11): 3,78$ mm; Abb. 3.9 D; FS: Sham/Celecoxib ( $n=15): 44,6 \%$ vs Sham/Placebo ( $n=11):$ 42,2 \%; Abb. 3.9 A).

Die Sterblichkeit der Kontrolltiere wurde durch die Celecoxibbehandlung nicht erhöht, keines dieser Tiere verstarb innerhalb des Beobachtungszeitraumes. In der Entwicklung des Körpergewichtes kam es nach 3 Wochen zu keiner signifikanten Veränderungen (Abb. 3.9 B). Andere Nebenwirkungen der medikamentösen Therapie konnten ebenfalls nicht beobachtet werden.

\subsubsection{Einfluss der Celecoxib-Behandlung auf TAC Tiere}

Nach zwei Wochen kam es bei den mit Placebo gefütterten TAC Tieren zu einer signifikanten Steigerung der linksventrikularen Masse (LVM: Placebo/TAC 4,36 $\pm 0,12(n=10)$ vs Placebo/Sham 6,78 $\pm 0,27(n=5) ; p<0,001 ;$ Abb. 3.9 E) und der Septumdicke (SW: Placebo/TAC 0,92 $\pm 0,03 \mathrm{~mm}(\mathrm{n}=5)$, vs Placebo/Sham 0,74 $\pm 0,01$ mm ( $n=11) ; p<0,0007$; Abb. 3.9 F) als Ausdruck einer deutlichen Herzhypertrophie.

Bereits nach zwei Wochen erhöhter Druckbelastung zeigten sich neben der Hypertrophie Zeichen einer beginnenden Maladaptation. Der linksventrikuläre enddiastolische Durchmesser (LVEDD) und der linksventrilkuläre endsystolische Durchmesser (LVESD) waren signifikant vergrößert im Sinne einer Ventrikel-Dilatation (LVESD: Placebo/Sham $2,05 \pm 0,04 \mathrm{~mm}(n=10)$ vs Placebo/TAC $3,66 \pm 0,08 \mathrm{~mm} \quad(n=5)$, $p<0,0001$; LVEDD: Placebo/Sham 3,65 $\pm 0,03 \mathrm{~mm}(\mathrm{n}=10)$ vs Placebo/TAC 4,50 $\pm 0,09$ $\mathrm{mm}(\mathrm{n}=5), \mathrm{p}<0,0005 ;$ Abb. $3.9 \mathrm{C}+\mathrm{D})$. 
A

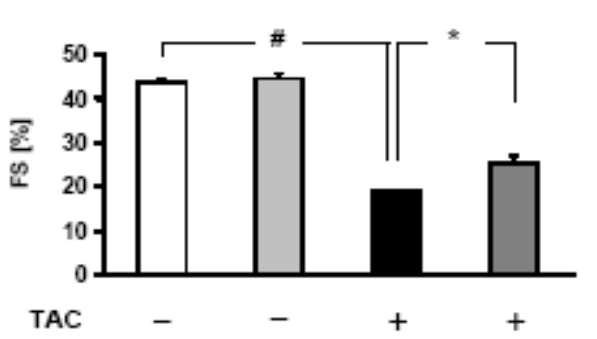

Celecoxib ( $\mathrm{mg} / \mathrm{kg} / \mathrm{d})$

n
B

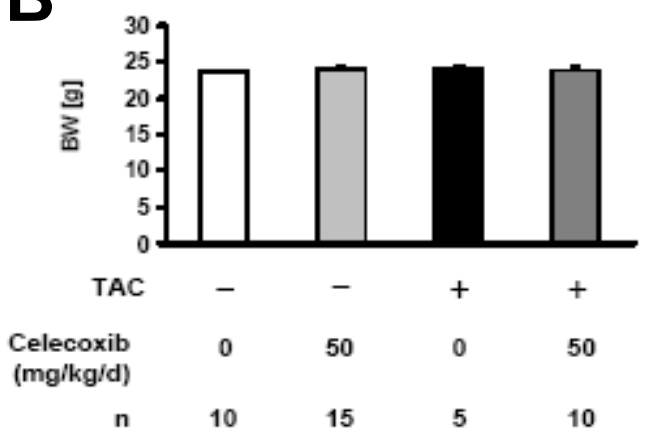

D

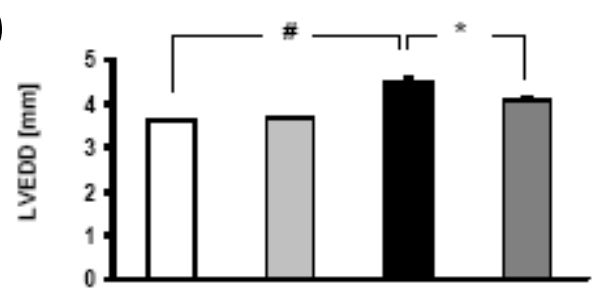

TAC $\quad-\quad+\quad+\quad+\quad+$

$\begin{array}{lllll}\text { Celecoxib } & 0 & 50 & 0 & 50\end{array}$

(mg/kg/d)

$\begin{array}{lllll}\text { n } & 10 & 15 & 5 & 10\end{array}$

$\mathbf{F}$

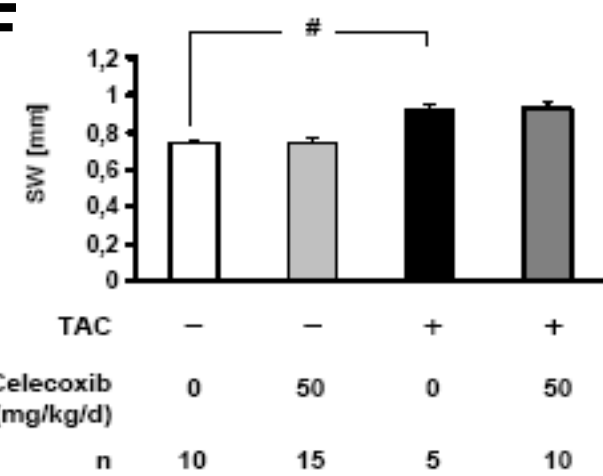

Abbildung 3.9 In-vivo-Versuche: Einfluss der Celecoxibbehandlung $(50 \mathrm{mg} / \mathrm{kg} / \mathrm{d})$ auf gebandete (TAC+) und Sham-operierte (TAC-)Tiere. Echokardiographische Parameter bestimmt 14 Tage nach OP; statistische Auswertung aller durchgeführten Untersuchungen: A Prozentuale Verkürzungsfraktion (FS): \# $p<0,00005$, * $p<0,01$; B Körpergewicht nach 3 Wochen; C linksventrikulärer endsystolischer Durchmesser (LVESD): \# $p<0,0001,{ }^{*} p<0,005$; D linksventrikulärer enddiastolischer Durchmesser (LVEDD): \# $p<0,0005,{ }^{*} p<0,01$; E kalkulierte linksventrikuläre Masse (LVM): \# $p<0,001$; F Septumdicke (SW): \# $p<0,0007$ 
Als Zeichen einer Funktionseinschränkung war die prozentuale Verkürzungsfraktion (FS) zwei Wochen nach der TAC-Operation signifikant erniedrigt (FS: Placebo/Sham 43,66 $\pm 0,99 \%(n=10)$ vs Placebo/TAC 18,82 $\pm 0,47 \% \quad(n=5), p<0,00001$; Abb. 3.9 A).

Durch die Behandlung mit Celecoxib konnte die Ventrikel-Dilatation signifikant reduziert werden (LVEDD: Celecoxib/TAC ( $n=19): 4,09 \pm 0,09 \mathrm{~mm}$ vs Placebo/TAC $(n=5)$ 4,50 $\pm 0,09 \mathrm{~mm} ; p<0,01$; LVESD: Celecoxib/TAC $(n=10): 3,06 \pm 0,13 \mathrm{~mm}$ vs Placebo/TAC ( $n=5): 3,67 \pm 0,08 \mathrm{~mm}, p<0,005$; Abb. $3.9 \mathrm{C}+\mathrm{D})$. Die kontraktile Funktion nach TAC war bei den Celecoxib-behandelten Tieren im Vergleich zu den mit Placebo gefütterten Tieren signifikant besser (FS: Celecoxib/TAC 25,41 $\pm 1,80 \%(n=10)$ vs Placebo/TAC 18,82 $\pm 0,47 \%(n=5) ; p<0,01 ;$ Abb. 3.9 A).

Bei den mit Celecoxib behandelten Tieren kam es zu einer verminderten Zunahme der linksventrikulären Masse, dieser Unterschied war jedoch nicht statistisch signifikant (LVM: Celecoxib/TAC 6,03 $\pm 0,28(n=10)$ vs Placebo/TAC 6,78 $\pm 0,27(n=5)$; $p=0,1$; Abb. 3.9 E).

Im Tierversuch konnten wir zeigen, dass die Behandlung mit Celecoxib Zeichen der maladaptiven Hypertrophie und Herzinsuffizienz nach Druckbelastung reduziert.

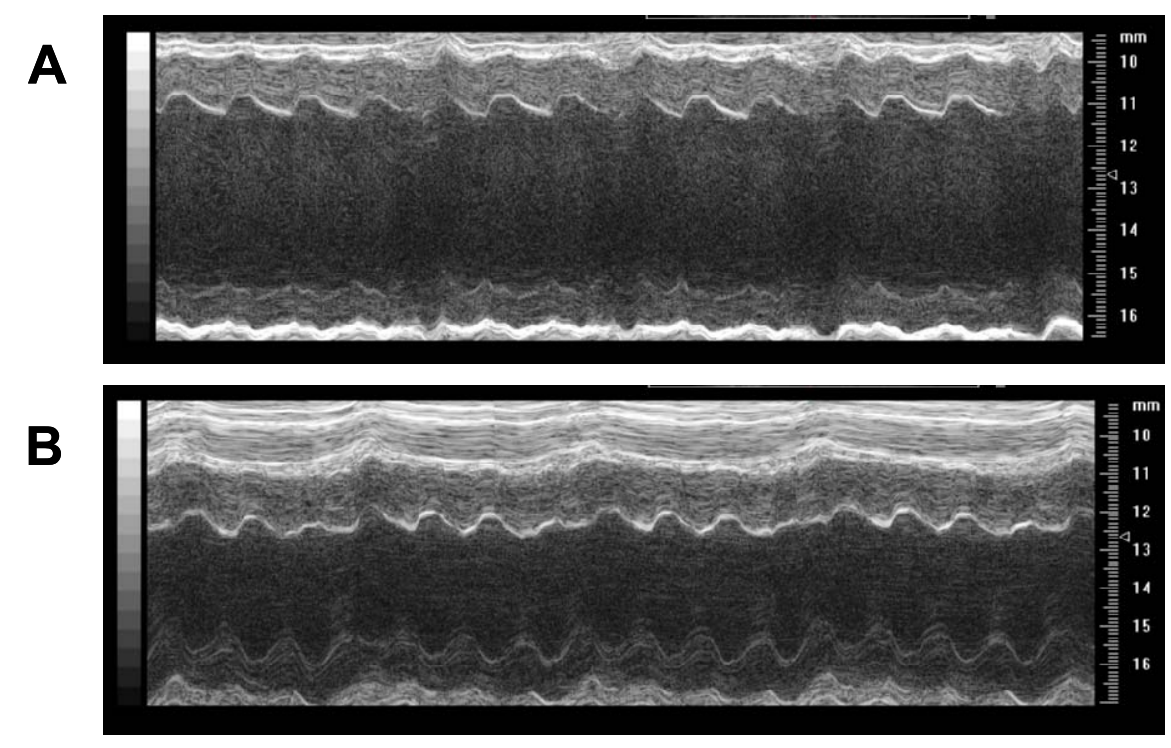

Abbildung 3.10 Original Echokardiographie- Aufzeichnungen 14 Tage nach TAC: A repräsentative Untersuchung einer mit Placebo gefütterten und TAC-Tieren: FS: 17,47 \%, LVEDD: 4,77 mm, LVESD: 3,67 mm; B repräsentative Untersuchung einer mit Celecoxib gefütterten und TAC-Tieren FS: 27,96 \%, LVEDD: 4,02 mm, LVESD: 3,06 mm. 


\subsubsection{Auswirkung auf die Sterblichkeit}

Um beurteilen zu können, ob sich die Verbesserung der kontraktilen Funktion und die reduzierte Dilatation unter Celecoxibtherapie auch in der Überlebenszeit der Tiere widerspiegelt, untersuchten wir die Mortalität in einer Kaplan-Meier Analyse.

Es zeigte sich, dass durch die Celecoxibbehandlung die Sterblichkeit acht Wochen nach Beginn der Druckbelastung signifikant gesenkt werden konnte (Placebo/TAC: $n=13$, Celecoxib/TAC: $n=14, p<0.05$, Abb. 3.11).

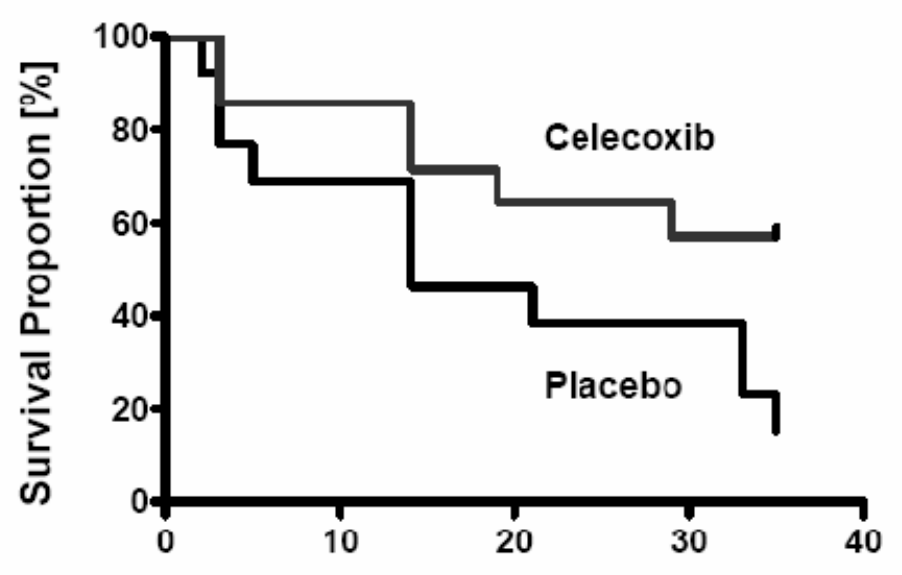

Time after TAC [d]

Abbildung 3.11 Auswirkung der Celecoxibbehandlung auf das prozentuale Überleben nach Banding-OP, Kaplan-Meier Analysen, $p<0,05$ 


\section{DISKUSSION}

\section{DISKUSSION}

\subsection{Rückblick auf die Fragestellungen der Arbeit}

1. Kann Celecoxib auch in Kardiomyozyten die Phosphorylierung von Akt regulieren? Celecoxib hemmt die Phosphorylierung von Akt in Kardiomyozyten zeit- und dosisabhängig.

2. Welche Auswirkungen hat diese Intervention auf die unterhalb von Akt gelegenen Signalwege? Auch in den distal von Akt gelegenen Komponenten (GSK-3 $\beta$ und p70S6-Kinase) lässt sich in vitro eine reduzierte Phosphorylierungsrate durch Celecoxib feststellen.

3. Ist der Effekt von Celecoxib auf den Akt-Signalweg unabhängig von der COX? Der Einsatz alternativer COX-Hemmer zeigt keinen Einfluss auf den Akt-Signalweg, sodass von einer COX-unabhängigen Wirkung von Celecoxib auszugehen ist.

4. Wie reguliert Celecoxib die Phosphorylierung von Akt? Celecoxib steigert die Aktivität von PTEN Dies führt zu einer vermehrten Dephosphorylierung von Akt.

5. Verändert eine Regulation des Akt-Signalweges in vitro die Hypertrophieantwort an isolierten Kardiomyozyten? Die Behandlung mit Celecoxib hemmt sowohl die gesteigerte Expression von BNP als auch eine gesteigerte Proteinbiosynthese signifikant.

6. Welchen Einfluss hat Celecoxib auf die Ausbildung und den Verlauf einer Hypertrophie in vivo? Celecoxib reduziert typische Merkmale einer maladaptiven Hypertrophie (Ventrikeldilatation und myokardiale Dysfunktion). Es hemmt den Übergang der Hypertrophie in eine Herzinsuffizienz.

7. Wie wirkt es sich auf die Überlebensrate nach Druckbelastung aus? Die Mortalität nach Druckbelastung wird durch die Behandlung mit Celecoxib signifikant reduziert.

\subsection{Akt und die Bedeutung der Herzhypertrophie}

Bis heute sind die genauen Mechanismen die zur Entwicklung einer Herzhypertrophie führen nicht abschließend erklärt. Für eine Vielzahl von verschiedenen Signalwegen ist ein hypertropher Einfluss auf Kardiomyozyten gesichert (Frey et Olson 2003; Frey et al. 2004; Selvetella et al. 2004; Heinecke et Molkentin 2006). Auch wenn einzelne Signalwege, wie der Akt -Signalweg, mit den einzelnen Komponen- 
ten der Signal-Kaskaden bis ins Detail beschrieben sind (Alessi et al. 1997; Seculic et al. 2000; Lu et al. 2003), sind das genaue Zusammenwirken und die Hierarchie der einzelnen Signalwege untereinander nicht vollständig bekannt.

Neben der Frage nach den beteiligten Regulationsmechanismen bleibt vor allem die genaue Bedeutung der Herzhypertrophie ungeklärt. Wurde die Herzhypertrophie lange als rein adaptive Reaktion und als notwendig für den Erhalt der Pumpfunktion beurteilt (Hood et al. 1968; Grossman et al. 1975), so wird heute die enge Korrelation der Hypertrophie mit der Entwicklung einer Herzinsuffizienz und der damit verbunden Mortalität und Morbidität stärker in den Vordergrund gestellt (Levy et al. 1990; Koren et al. 1991; Sullivan et al. 1993; Vakili et al. 2001). Bedeutend hierfür ist die Tatsache, dass diverse Studien zeigen, dass transgen veränderte Tiere, die keine Hypertrophie entwickeln können, auf vermehrte Herzarbeit nicht mit einer Verschlechterung der Herzleistung reagieren (Hill et al. 2000; Rothermel et al. 2001; Espositos et al. 2002; Hill et al. 2002), die Entstehung der Herzhypertrophie für den Erhalt der Pumpfunktion des Herzens also nicht notwendig erscheint.

In Anbetracht der Ergebnisse stellt sich die Frage nach der Bedeutung der Herzhypertrophie als fraglich notwendige Antwort auf vermehrte Herzarbeit und die Bedeutung des Akt-Signalweges als Mediator einer reinen Hypertrophie oder als Vorstufe der Herzinsuffizienz.

\subsubsection{Adaptive versus maladaptive Hypertrophie}

So divergent wie die Bedeutung der Herzhypertrophie diskutiert wird, zeigen sich auch die Ergebnisse der Studien, die die Auswirkung des Akt-Signalweges auf den lebenden Organismus untersuchen. Eine vermehrte Aktivität von Akt führt am Herzen zu einer deutlichen Hypertrophiereaktion (Matsui et al. 2002; Shioi et al. 2002; Tanijama et al. 2004; Shiojima et al. 2005).

Die meisten Erkenntnisse zur Bedeutung des Akt-Signalweges bei der Entstehung der Herzhypertrophie stammen aus Studien mit transgen veränderten Tieren, die eine dauerhafte Überexpression von Akt aufweisen. Die Tiere entwickeln eine deutliche Hypertrophie der Herzen, die zu Beginn keine Funktionseinschränkung oder Dilatation mit sich bringt. Im Verlauf beschreiben jedoch verschiedene Arbeitsgruppen den Übergang der Hypertrophie in eine Herzinsuffizienz mit Dilatation, Funktionsverlusten und einer erhöhten Sterblichkeit (Shioi et al. 2002; Tanijama et al. 
2004; Shiojima et al. 2005). Histologisch zeigt sich eine vermehrte Fibrose im Sinne einer pathologischen Herzhypertrophie (Shioi et al. 2001; Shiojima et al. 2005). Im Gegensatz zu diesen Ergebnissen stehen Beobachtungen, die auf eine Bedeutung des Akt-Signalweges bei der Vermittlung einer rein physiologischen Hypertrophieantwort hinweisen. Verstärkte körperliche Aktivität führt zu einer vermehrten Akt-Phosphorylierung (Mc Mullen et al. 2003), wohingegen transgen veränderte Mäuse mit einer eingeschränkten Aktivität der Akt nur eine abgeschwächte Hypertrophieantwort auf regelmäßiges Schwimmtraining entwickeln können (McMullen et al. 2003; deBosch et al. 2006). Auch bei der postnatalen Herzentwicklung scheint der Akt-Signalweg eine Rolle zu spielen (Shiojima et al. 2002). Es wird sogar eine verbesserte Resistenz gegen toxische Einflüsse mit einer signifikant geringeren Apoptoserate beschrieben bei transgenen Tieren mit einer dauerhaft erhöhten AktAktivität, sowie eine verbesserte Toleranz gegenüber ischämischer Schädigung (Matsui et al. 2002; Taniyama et al. 2004).

Einige Studien mit erhöhter Akt-Aktivität bei transgenen Tieren beschreiben eine Entwicklung der Herzhypertrophie, die zu keinem Zeitpunkt in eine Dilatation übergeht oder eine verminderte Funktion des linken Ventrikels zeigt (Condorelli et al. 2002; Matsui et al. 2002).

In der vorliegenden Arbeit profitierten die Tiere von der parallel zum Hypertrophiestimulus gegebenen Celecoxibtherapie. Das Ausmaß der Herzhypertrophie wird nur wenig verändert, der Übergang in die Herzinsuffizienzwird jedoch signifikant gehemmt. Die Hemmung des Akt-Signalweges scheint im Zusammenhang zu stehen mit dem Übergang der Herzhypertrophie in die Herzinsuffizienz.

Auf der einen Seite scheint eine Aktivierung des Akt-Signalweges also ein physiologischer Prozess im Rahmen des postnatalen Wachstums und eines körperlichen Trainings zu sein, auf der anderen Seite aber auch eine Bedeutung bei der Entwicklung der pathologischen Herzhypertrophie und den damit verbundenen fatalen Folgen zu haben.

\subsubsection{Welche Bedeutung hat das Ausmaß der Akt-Aktivität?}

Als möglicher Varianzparameter erscheint das Maß der Überexpression. Vergleicht man Studien, in denen transgene Tiere mit einer dauerhaft erhöhten Akt-Aktivität untersucht wurden, so fällt auf, dass sich die Versuchsprotokolle in der Quantität der erreichten Akt-Aktivität unterscheiden. In den Studien, die über eine Entwicklung der 
Herzhypertrophie hin zur Herzinsuffizienz berichten, wurde eine um das 15- bis 80 fach gesteigerte Akt-Aktivität gegenüber dem Wildtyp erreicht (Shioi et al. 2002; Nagoshi et al.2005; Shiojima et al. 2005). Im Vergleich dazu beobachtet man bei Mäusen, die unter regelmäßigem Schwimmtraining eine physiologische Herzhypertrophie entwickeln, nur eine Verdopplung der Akt-Aktivität (Mc Mullen et al. 2003). So scheint eine moderate Steigerungen der Akt-Aktivität mit einem physiologischen Verlauf der Hypertrophie assoziiert (Shioi et al. 2000; Yamashita et al. 2001; McMullen et al. 2003), eine starke Überexpression von Akt führt zu einer pathologischen Hypertrophie und zum Übergang in eine Herzinsuffizienz mit Einschränkung der Pumpfunktion, Ventrikeldilatation und erhöhter Mortalität (Shioi et al. 2002; Nagoshi et al.2005; Shiojima et al. 2005).

Ein weiterer Einflussfaktor scheint die zeitliche Ausdehnung der Akt-Überexpression zu sein. Wichtige Erkenntnisse in dieser Frage erbrachten Shiojima et al. mit der Entwicklung eines Tiermodels mit einer Doxorubicin gesteuert induzierbaren Überexpression von Akt. Durch diese Versuchsbedingungen ist es möglich, eine AktÜberexpression über eine definierte Zeit zu induzieren, diese aber auch wieder zu beenden. Schon die Induktion der Akt-Überexpression über einen Zeitraum von zwei Wochen führt zu einer Herzhypertrophie, jedoch ohne eine Einschränkung der Pumpfunktion und ohne eine vermehrte Fibrose. Diese Hypertrophie ist nach Beendigung des Stimulus vollständig reversibel. Erst eine längerfristige Hochregulation der Akt über 6 Wochen führt zu einer deutlichen Verschlechterung der linksventrikulären Funktion, vermehrter Fibrose und erhöhter Sterblichkeit. In diesem Fall sind die entstandene Hypertrophie und die damit verbundenen Komplikationen auch nach Normalisierung der Akt-Expression nicht mehr vollständig reversibel (Shiojima et al. 2005).

Untersuchungen humaner Gewebeproben zeigen ebenfalls einen Zusammenhang zwischen dem Ausmaß der Akt-Überexpression und dem Übergang der Hypertrophie in eine Herzinsuffizienz. In hypertrophem humanem Myokard lässt sich zwar eine Überexpression von Akt feststellen, aber erst der Übergang in die Herzinsuffizienz ist mit einem massiven Anstieg von Akt assoziiert (Haq et al. 2001; Baba et al. 2003).

Eine vermehrte Akt-Aktivität scheint also auch bei vergleichbarem Ausmaß der Überstimulation sehr unterschiedliche Ausprägungen und Folgen der Hypertrophie hervorzurufen, in Abhängigkeit von der zeitlichen Komponente der Akt-Aktivierung. 
Eine Kategorisierung des Akt-Signalweges als ausschließlicher Mediator einer pathologischen oder physiologischen Herzhypertrophie ist also nicht möglich, sondern vielmehr scheinen Ausmaß und Dauer der vermehrten Akt-Aktivität ausschlaggebend zu sein. Eine kontrollierte Reduktion der Aktivität der Akt könnte dementsprechend ein gutes Werkzeug sein, um ein Fortschreiten einer Herzhypertrophie und den Übergang in eine Herzinsuffizienz zu vermeiden ohne dabei die normale Herzentwicklung und physiologische Anpassungsmechanismen zu stören.

\subsection{Celecoxib als Therapieoption}

\subsubsection{Pharmakologische Modulationsmöglichkeiten}

Um die Phosphorylierung von Akt kontrolliert steuern zu können, wäre eine gezielte pharmakologische Modulation sinnvoll. Durch variieren der Dosierungen und der Anwendungsdauer könnte die Aktivität des Akt-Signalweges den physiologischen Gegebenheiten angepasst werden. Bis jetzt gibt es hierfür jedoch keinen geeigneten Wirkstoff, der beim Menschen regelrecht zum Einsatz kommen könnte.

In Laborexperimenten zur Untersuchung des Akt-Signalweges wird der PI3-Kinase Hemmstoff Wortmannin und der mTor-Inhibitor Rapamycin zur pharmakologischen Modulation verwendet. Der Einsatz von Wortmannin an isolierten Myozyten zeigte eine Reduktion indirekter Hypertrophiezeichen (Rabkin et al 1997; Schlüter et al. 1998; Kenessey et Ojmanaa 2005), ein therapeutischer Einsatz von Wortmannin beim Menschen ist jedoch auf Grund seiner starken Nebenwirkungen insbesondere der Lebertoxizität nicht möglich (Ihle et al. 2004; Howes et al. 2007). Für den kürzlich zur Krebstherapie entwickelten nebenwirkungsärmeren Hemmstoff der PI3Kinase PX-866 gibt es bis jetzt keinerlei Ergebnisse über die Auswirkung im AktSignalweg in Kardiomyozyten.

Rapamycin nimmt nur Einfluss auf den mTor regulierten Anteil des AktSignalweges, beeinflusst aber ebenfalls die hypertrophe Antwort von Kardiomyozyten auf unterschiedlichste Stimuli in vitro (Ha et al. 2005; Kuzman et al. 2007) und vermindert eine Hypertrophieentwicklung in vivo (Shioi et al. 2003; McMullen et al. 2004; Ha et al. 2005; Kuzman et al. 2007). Rapamycin ist für den therapeutischen Einsatz beim Menschen zugelassen und wird als Immunsuppresivum nach Transplantationen (Stegall et al. 2003; Morard et al. 2007) und zur Beschichtung von Koronar-Stents (Morice et al. 2002) eingesetzt. Ein großes Problem stellt jedoch auch 
hier das Nebenwirkungsspektrum dar, insbesondere die Immunsuppression mit erhöhter Infektionsgefahr (Kuypers 2005).

Ein regelmäßiger Einsatz von Rapamycin oder Wortmannin als systemische antihypertrophe Therapie beim Menschen scheint unter den gegebenen Umständen nicht möglich.

\subsubsection{Die Diskussion um selektive COX-2-Hemmer}

Die selektiven COX-2 Hemmer sind in den letzen Jahren sehr stark in die öffentliche Kritik geraten, das ihre regelmäßige Einnahme mit einem erhöhten Risiko für kardiovaskuläre Ereignisse assoziiert ist. Im September 2004 gab die Firma Merck den Rückruf des zu dem Zeitpunkt meist verschriebenen selektiven COX-2 Hemmer Rofecoxib $\left(V_{i o x}{ }^{\circledR}\right)$ bekannt. In mehreren Studien war ein vermehrtes Auftreten von kardiovaskulären Nebenwirkungen unter Rofecoxib-Therapie im Vergleich zu anderen NSAIDs aufgefallen (Bombardier et al. 2000; Mukerjee et al. 2001).

In der darauf folgenden Debatte wurde häufig ein so genannter Klasseneffekt aller selektiven COX-2 Hemmer in Bezug auf ein erhöhtes kardiovaskuläres Risiko diskutiert. Celecoxib geriet in Verruf obwohl weder in der VIGOR-Studie noch in der CLASS-Studie ein erhöhtes Herzinfarktrisiko für Celecoxib behandelte Patienten im Vergleich zur Kontrollgruppe gezeigt werden konnte (Bombardier et al. 2000; Silverstein et al. 2000). Wiederbelebt wurde die Diskussion, als 2006 in einer Studie zur Prävention von kolorektalen Adenomen eine erhöhte Rate an kardiovaskulären Ereignissen bei Celecoxib behandelten versus Placebo behandelten Patienten auffiel (Bertagnolli et al 2006). Weitere Studien konnten dies jedoch nicht bestätigen (Solomon et al. 2004; Graham et al. 2005; Arber et al. 2006) und auch zwei neue große Metaanalysen konnten kein vermehrtes Auftreten von kardiovaskulären Ereignissen unter Celecoxibeinnahme finden (McGettigan et Henry 2006; White et al. 2007).

Die Tatsache, dass Celecoxib ursprünglich entwickelt wurde, um ASS und andere NSAIDs in ihrer Aufgabe als suffiziente antiinflammatorische und analgetische Therapie verbunden mit geringeren gastrointestinalen Nebenwirkungen zu ersetzen, führt häufig zu der Fehlinterpretation, dass Celecoxib auch die antikoagulative Komponente von ASS ersetzt. Die Thromboxansynthese, die von Aspirin gehemmt wird, ist COX-1 abhängig. Somit hat Celecoxib als selektiver Hemmer der COX-2 keinen Einfluss auf die Thrombozytenaggregation (Leese et al. 2000). Eine niedrig dosierte 
Aspirintherapie in präventiver Absicht zum Beispiel bei koronaren Herzkrankungen kann also nicht durch Celecoxib ersetzt werden.

Auch eine vermehrte Hypertonieneigung unter Celecoxibtherapie, vermehrte Ödemneigung oder eine renale Dysfunktion, wie sie für Rofecoxib beschrieben sind, konnten für Celecoxib nicht nachgewiesen werden (Zhang et al. 2006; Whelton et al. 2006; Solomon et al. 2006; Wang et al. 2007). Unter der von uns im Tierversuch verwendeten Dosis Celecoxib (50 mg/kg/d) kam es bei den Mäusen zu keiner Zunahme des Körpergewichtes als Hinweis auf eine eingeschränkte Nierenfunktion oder Ödembildung.

\subsection{Zukunftsperspektiven}

Im Zuge der immer älter werdenden Bevölkerung spielt die Herzinsuffizienz als im Alter gehäuft auftretende Erkrankung eine immer größer werdende Rolle. Die 5Jahres-Überlebensrate liegt bei 59 \%, das Risiko am plötzlichen Herztod zu versterben ist um das 2-fache erhöht (Mosterd et al. 2001). Eine kausale Therapie der Herzinsuffizienz ist in Abhängigkeit von den auslösenden Faktoren nur teilweise möglich. Symptomatik und Prognose konnten durch die Weiterentwicklung der medikamentösen und elektrischen Therapien verbessert werden. Trotzdem bleibt die Herzinsuffizienz eine schwerwiegende Erkrankung. Umso wichtiger erscheint es, schon die Entstehung der Herzinsuffizienz zu verhindern.

Im Tierversuch konnten wir zeigen, dass eine Behandlung mit Celecoxib die Entwicklung einer Herzinsuffizienz aus einer Hypertrophie verzögert und somit das Überleben signifikant verlängern kann. Mittels Celecoxib scheint die Hemmung einer überschießenden Akt-Aktivität möglich, ohne eine Störung der Akt abhängigen physiologischen Vorgänge zu verursachen. Gezielte Studien, die untersuchen, ob eine solche Therapie auch beim Menschen erfolgreich sein könnte, fehlen.

Hinweis für einen protektiven Effekt von Celecoxib gibt eine Studie von Mamdani et al von 2003., die zeigt, dass Patienten, die regelmäßig Celecoxib einnehmen, signifikant seltener auf Grund von dekompensierter Herzinsuffizienz stationär im Krankenhaus aufgenommen werden als Patienten, die Rofecoxib oder andere NSAIDs einnehmen. Dies könnte ein Hinweis sein auf einen positiven Effekt von Celecoxib auf den Verlauf einer Herzinsuffizienz.

Auf dem Gebiet der Proliferation von Zellen der Gefäßwand gibt es bereits erste Erfahrungen mit dem Einsatz von Celecoxib als antiproliferative Therapie beim 
Menschen. Im Tierversuch konnte ein hemmender Effekt von Celecoxib auf die Proliferation von glatten Muskelzellen nach Intimaverletzung gezeigt werden (Yang et al. 2004). In einem weiteren Schritt konnte gezeigt werden, dass dieses Model auf den Menschen zu übertragen ist. Durch die prophylaktische Gabe von 200 mg Celecoxib pro Tag nach drug-eluting Stent Implantation über 6 Monate konnte eine signifikant geminderte Restenose-Rate erreicht werden (Koo et al. 2007).

Entgegen der Diskussion um ein erhöhtes kardiovaskuläres Risiko der regelmäßigen Celecoxibtherapie besonders bei Patienten mit koronaren Herzerkrankungen konnte in diesem Hoch-Risiko-Kollektiv bei gleichzeitiger Gabe von ASS und Clopidogrel zur adäquaten Thrombozytenaggregation kein vermehrtes Auftreten von kardiovaskulären Ereignissen beobachtet werden. Der Benefit der Celecoxibbehandlung als antiproliferative Therapie stand eindeutig im Vordergrund.

Dies könnte ein Anreiz sein, auch in Bezug auf eine antihypertrophe und Herzinsuffizienz verzögernde Therapie mit Celecoxib als Hemmer des Akt-Signalweges weiter zu forschen. Wichtige Voraussetzung ist hierfür ein detailliertes Wissen über die zur Hypertrophie führenden Signalwege und die Differenzierung der unterschiedlichen Hypertrophiearten und ihrer Auslöser. 


\section{ZUSAMMENFASSUNG}

\section{ZUSAMMENFASSUNG}

Eine vermehrte Aktivität der Kinase Akt führt zu einer kardialen Hypertrophie. Der Übergang von der Hypertrophie in die Herzinsuffizienz ist ebenfalls mit einer vermehrten Aktivität von Akt assoziiert. Dies ist auch in Gewebeproben von humanen insuffizienten Herzen nachweisbar.

In der vorliegenden Arbeit konnte erstmals gezeigt werden, dass der COX 2Inhibitor Celecoxib die Phosphorylierung des Signalmoleküls Akt in Kardiomyozyten hemmt. Hierdurch werden auch die distalen Komponenten der Akt-Signalkaskade, GSK-3ß und p70S6-Kinase, gehemmt. Der Effekt ist zeit- und konzentrationsabhängig und unabhängig von der COX-inhibierenden Wirkung der Substanz. Es konnte gezeigt werden, dass die Hemmung von Akt durch Celecoxib durch eine Zunahme der Phosphatase-Aktivität von PTEN vermittelt wird.

Auf zellulärer Ebene wurden die Proteinsyntheseleistung und die BNP-Expression, etablierte Surrogatparameter der kardialen Hypertrophie, durch Celecoxib gehemmt. Am Mausmodell konnte gezeigt werden, dass die pharmakologisch kontrollierte Hemmung einer übermäßigen Akt-Aktivität die linksventrikuläre Dilatation und kontraktile Dysfunktion nach Druckbelastung reduziert und somit charakteristische Merkmale einer maladaptiven Hypertrophie und Herzinsuffizienz abschwächt. Hierdurch wurde die Mortalität reduziert.

Celecoxib scheint ein geeignetes Werkzeug zur gezielten pharmakologischen Regulation des Akt-Signalweges zu sein. Durch eine moderate Hemmung der AktAktivität könnte eine übermäßige Aktivierung abgemildert werden, ohne Akt abhängige physiologische Vorgänge zu stören. 


\section{ANHANG}

\section{ANHANG}

\section{Abbildungsverzeichnis}

Abbildung 1.1 Überblick über den Akt-Signalweg

Abbildung 3.1 Konzentrationsabhängiger Effekt von Celecoxib auf

die Phosphorylierung von Akt (Inkubationszeit $1 \mathrm{~h}$ )

Abbildung 3.2 Zeitabhängiger Effekt von Celecoxib auf die Phosphorylierung von Akt (Inkubationszeit 24 h)

Abbildung 3.3 Konzentrationabhängiger Effekt von Celecoxib auf die Phosphorylierung von GSK-3 $\beta$ und p70S6-Kinase (Inkubationszeit $1 \mathrm{~h}$ )

Abbildung 3.4 Wirkung von ASS auf die Phosphorylierung der Akt (Inkubationszeit 1h)

Abbildung 3.5 Konzentrationsabhängiger Effekt von Celecoxib auf die Phosphorylierung von PTEN (Inkubationszeit $1 \mathrm{~h}$ )

Abbildung 3.6 Auswirkung einer Celecoxibbehandlung auf die Proteinsyntheseleistung (Inkubationszeit $24 \mathrm{~h}$ )

Abbildung 3.7 Auswirkung einer Celecoxibbehandlung auf die BNPm-RNA Expression (Inkubationszeit $24 \mathrm{~h}$ )

Abbildung 3.8 Einfluss von Celecoxib auf die Expression der SERCA-2A (Inkubationszeit 24) 

nach TAC

Abbildung 3.11 Auswirkung der Celecoxibbehandlung auf das prozentuale Überleben nach TAC

\section{Tabellenverzeichnis}

Tabelle 2.1 Konzentrationen 1. Antikörper für die Immunfärbung

S. 21

Tabelle 2.2 Konzentrationen 2. Antikörper für Immunfärbung

S. 22 


\section{LITERATURVERZEICHNIS}

\section{LITERATURVERZEICHNIS}

Alessi DR, Andjelkovic M, Caudwell B, Cron P, Morrice N, Cohen P, Hemmings BA (1996): Mechanism of activation of protein kinase $B$ by insulin and IGF-1; EMBO J 15(23):6541-6551

Alessi DR, James SR, Downes P, Holmes AB, Gaffney PRJ, Reese CB, Cohen $P$ (1997): Characterization of a 3-phosphoinositide-dependent protein kinase which phosphorylates and activates protein kinase Ba; Curr Biol 7:261-269

Almeida SS, Azevedo A, Castro A, Frioes F, Freitas J, Ferreira A, Bettencourt $P$ (2002): B-Type natriuretic peptide is related to left ventricular mass in hypertensive patients but not in athletes; Cardiology 98(3):113-115

Anderson KE, Coadwell J, Stephens LR, Hawkins PT (1998):Translocation of PDK-1 to the plasma membrane is important in allowing PDK-1 to activate protein kinase B; Curr Biol 8:684-691

Antos CL, McKinsey TA, Frey N, Kutschke W, McAnally J, Shelton JM, Richardson JA, Hill JA, Olson EN (2002): Activated glycogen synthase-3 $\beta$ suppresses cardiac hypertrophy in vivo; Proc Natl Acad Sci U S A 99:907-912

Arber N, Eagle CJ, Spicak J, Racz I, Dite P, Hajer J, Zavoral M, Lechuga MJ, Gerletti P, Tang J (2006): Celecoxib for prevention of the colorectal adenomatous polyps; N Eng J Med 355(9):885-895

Arico S, Pattingre S, Bauvy C, Gane P, Barbat A, Codogno P, Ogier-Denise E (2002): Induces apoptosis by inhibiting 3-phosphoinositide-dependent protein kinase 1 activity in the human colon cancer HT-29 line; J Biol Chem 277:27613-27621

Baba HA, Stypmann J, Grabellus F, Kirchhof P, Sokoll A, Schäfers M, Takeda A, Wilhelm MJ, Levkau B (2003): Dynamik regulation of MEK/Erks and Akt/GSK$3 ß$ in human endstage heart failure after left ventricular mechanical support: Myocardial mechanotransduction-sensitivity as a possible molecular mechanism; Cardiovasc Res 59:390-399 
Baron JA, Sandler RS, Haile RW, Ahnen D, Bresalier R, McKeown-Eyssen G, Summers RW, Rothstein R, Burke CA, Snover DC (2003): A randomized trial of aspirin to prevent colorectal adenomas; N Eng J Med 348(10):891-899

Beals CR, Sheridan CM, Turck CW, Gardner P, Crabtree GR (1997): Nuclear export of NF-Atc enhanced by glycogen synthase kinase-3; Science 275(5308): $1930-1934$

Bertagnolli MM, Craig JE, Zauber AG, Redston M, Solomon SD, Tang J, Rosenstein RB, Wittes J, Corle D, Hawk ET (2006): Celecoxib for the prevention of sporadic coolorectal adenomas; N Eng J Med 355:873-884

Bombardier C, Laine L, Reicin A, Shapiro D, Burgos-Vargas R, Davis B, Day R, Ferraz MB, Hawkey CJ, Schnitzer TJ; VIGOR Study Group (2000): Comparson of upper gastrointestinal toxicity of rofecoxib and naproxen in patients with rheumatoid arthritis, VIGOR Study Group; N Eng J Med 343(21):1520-1528

Burnett PE, Barrow RK, Cohen NA, Snyder SH, Sabatini DM (1998): RAFT1 phosphorylation of the translational regulators p70 S6 kinase and 4E-BP1; Proc Natl Acad Sci U S A 95(4):1432-1437

Cohen P, Frame S (2001): The renaissance of GSK3; Nat Rev Mol Cell Biol 2(10): $769-776$

Condorelli G, Drusco A, Stassi G, Bellacosa A, Roncarati M, Laccarino G, Russo MA, Gu Y, Chung C, Rosss J (2002):Akt induces enhanced myocardial contractility and cell size in vivo in transgenic mice; Proc Natl Acad Sci U S A 99:12333-12338

Cowie MR, Wood DA, Coats AJ, Thompson SG, Poole-Wilson PA, Suresh V, Sutton GC (1999): Incidence and aetiology of heart failure; a population-based study; Eur Heart J 20(6):421-428

Crabtree GR, Olson EN (2002): NFAT signaling: choreographing the social lives of cells; Cell 109 Suppl:S67-79 
Crofford LJ (1997): COX-1 and COX-2 tissue expression: implications and predictions; J Rheumatol Suppl 49:15-19

Cross DAE, Alessi DR, Cohen P, Andjelkovich M, Hemmings BA (1995): Inhibition of glycogen synthase kinase-3 by insulin mediated by protein kinase B; Nature 378:785-788

De Bosch B, Treskov I, Lupu TS, Weinheimer C, Courtois M, Muslin AJ (2006): Akt1 is required for physiological cardiac growth; Circulation 113(17):2097-2104

Dubois RN, Abramson SB, Crofford L, Gupta RA, Simon LS, Van De Putte LB, Lipsky PE (1998): Cyclooxygenase in biology and disease; FASEB J 12(12):10631073

Eberhart CE, Coffey RJ, Radhika A, Giarello FM, Ferrenbach S, DuBois RN (1994): Up-regulation of cyclooxegenase 2 gene expression in human colorectal adenomas and adenocarinomas; Gastroenterology 107(4):1183-1188

Eghbali M, Deva R, Alioua A, Minosyan TY, Ruan H, Wang Y, Toro L, Stefani E (2005): Molecular and functional signature of heart hypertrophy during pregnancy; Circ Res 96(11):1208-1216

Esposito G, Rapucciuolo A, Nagad Prasad SV, Takaoa H, Thomas SA, Koch WJ, Rockman HA (2002): Genetic alterations that inhibit in vivo pressure-overload hypertrophy prevent cardiac dysfunction despite increased wall stress; Circulation $\underline{105: 85-92}$

Frey N, Olson EN (2003): Cardiac Hypertrophy: The good, the bad, and the ugly; Annu Rev Physiol 65:45-79

Frey N, Katus HA, Olson EN, Hill JA (2004): Hypertrophy of the heart; Circulation 109:1580-1589

Graham DJ, Campen D, Spence M, Cheetham C, Levy G, Shoor S, Ray WA (2005): Risk of acute myocardial infarction and sudden cardiac death in patientes treated with cyclo-oxygenase 2 selective and non-selective non-steroidal antiinflammatory drugs: nested case-control study; Lancet $\underline{365}$ : 475-81 
Grossman W, McLaurin LP, Stefadouros MA (1975): Wall stress and patterns of hypertrophy in the human left ventricle; J Clin Invest 56(1):55-64

Ha T, Li Y, Gao X, McMullen JR, Shioi T, Izumo S, Kelley JL,Zhao A, Haddad GE, Li C (2005): Attenuation of cardiac hypertrophy by inhibiting both mTor and NfkappaB activation in vivo; Free Radic Biol Med 39(12): 1570-1580

Haq S, Choukroun G, Lim H, Tymitz KM, del Monte F, Gwathmey J, Grazette L, Michael A, Hajjar R, Molkentin JD (2001): Differential activation of signal transduction pathways in human hearts with hypertrophy versus advanced heart failure; Circulation 103:670-677

Hardt SE, Sadoshima J (2002): Glycogen synthase kinase-3ß: A novel regulator of cardiac hypertrophy and development; Circ Res 90:1055-1063

Hasenfuss G (1998): Alterations of calcium-regulatory proteins in heart failure; Cardiovasc $\operatorname{Res}$ 37:279-289

Heinecke J, Molkentin D (2006): Regulation of cardiac hypertrophy by intracellular signaling pathways; Nat Rev Mol Cell Biol 7:589-600

Hill JA, Karimi M, Kutschke W, Davisson RL, Zimmermann K, Wang Z, Kerber RE, Weiss RM (2000): Cardiac hypertrophy is not a required compensatory response to short-term pressure overload; Circulation 101(24):2863-2869

Hill JA, Rothermel B, Yoo KD, Cabuay B, Demetroulis E, Weiss RM, Kutschke W, Bassel-Duby R, Williams RS (2002): Target inhibition of calcineurin in pressure-overload cardic hypertrohie; J Biol Chem 277:10251-10255

Hood WP, Rackley CE, Rolett EL (1968): Wall stress in the normal and hypertrophied human left ventricle; Am J Cardiol 22(4):550-558 
Howes AL, Chiang GG, Lang ES, Ho CB, Powis G, Vuori K, Abraham RT (2007):The phosphatidylinositol 3-kinase inhibitor, PX-866, is a potent inhibitor of cancer cell motility and growth in three-dimensional cultures; Mol Cancer Ther 6(9): $1-10$

Hsu AL, Ching TT, Wang DS, Song X, Rangnekar VM, Chen CS (2000): The cyclooxygenase-2 inhibitor celecoxib induces apoptosis by blocking Akt activation in human prostate cancer cells independently of bcl-2; J Biol Chem 275:11397-11403

Ihle NT, Williams R, Chow S, Chew W, Berggren MI, Puine-Murrieta G, Minion DJ, Halter RJ, Wipf P, Abraham R, Kirkpatrick L, Powis G (2004); Molecular pharmacology and antitumor activity of PX-866, a novel inhibitor of phosphoinositide-3-kinase signaling; Mol Cancer Ther 3(7):763-772

Izumo S, Nadal-Ginard B, Mahadavi V (1988): Protooncogene induction and reprogramming of cardiac gene expression produced by pressure overload; Proc Natl Acad Sci U S A 85(2):339-343

Jourdain P, Funck F, Bellorini M, Guillard N, Loiret J, Thebault B, Desnos M, Duboc D (2003): Bedside B-type natriuretic peptide and functional capacity in chronic heart failure; Eur J Heart Fail $\underline{\text { (2): } 155-60}$

Kajsutra J, Leri A, Finato N, Di Loreto C, Feltrami CA, Anversa P (1998): Myocyte proliferation in end-stage cardiac failure in humans; Proc Natl Acad Sci USA 95:8801-8805

Kenessey A, Ojamaa K (2006): Thyroid hormone stimulates protein synthesis in the cardiomyocyte by activation the Akt-mTor and p70S6K pathway; J Biol Chem 281(30):20666-20672

Koo BK, Kim YS, Park KW, Yang HM, Kwon DA, Chung JW, Hahn JY, Lee HY, Park JS, Kim HS (2007): Effect of celecoxib on restenosis after coronary angioplasty with taxus stent (corea-taxus trial): an open-label randomised controlled study; Lancet $\underline{370}: 567-574$ 
Koren MJ, Devereux RB, Casale PN, Savage DD, Laragh JH (1991): Relation of left ventricular mass and mortility in uncomplicated essential hypertension; Ann Intern Med 114: 345-352

Kune GA, Kune S, Watson LF (1988): Colorectal cancer risk, chronic illnesses, opertations, and medications: case control results from the Melbourne Colorectal Cancer Study; Cancer Res 48(15):4399-4404

Kupari M, Turto H, Lommi J (2005): Left ventricular hypertrophy in aortic valve stenosis: preventive or promotive of systolic dysfunction and heart failure; Eur Heart J 26 $: 1790-1796$

Kuypers DR (2005): Benefit-risk assessment of sirolimus in renal transplantation; Drug Saf 28(2): $153-181$

Kuzman JA, O'Connnell TD, Gerdes AM (2007): Rapamycin prevents thyroid hormone-induced cardiac hypertrophy; Endocrinology 148(7):3477-3484

Lee SC, Stevens TL, Sandberg SM, Heublein DM, Nelson SM, Jougasaki M, Redfield MM, Burnett JC Jr. (2002): The potential of brain natriuretic peptide as a biomarker for New York Heart Association class during the outpatient treatment of heart failure; J Card Fail 8(3):149-154

Leese PT, Hubbard RC, Karim A, Isakson PC, Yu SS, Geis GS (2000): Effects of celecoxib, a novel cyclooxygenase-2 inhibitor on platelet function in healthy adults: a randomized, controlled trial; J Clin Pharmacol 40:124-132

Levy D, Garrison RJ, Savage DD, Kannel WB, Castelli WP (1990): Prognistic implications of echocardiographically determined left ventricular mass in the Framingham Heart Study; N Eng J Med 322:1561-1566

Lim DS, Roberts R, Marian AJ (2001): Expression profiling of cardiac genes in human hypertrophic cardiomyopathy: insight into the pathogenesis of phenotypes; $J$ Am Coll Cardiol 38(4):1175-1180 
Lip GY, Felmeden DC, Li-Saw-Hee FL, Beevers DG (2000): Hypertensive heart disease. A complex syndrom or a hypertension cardiomyopathy; Eur Heart $\mathrm{J}$ 21(20): $1653-1665$

Lu Y, Yu Q, Liu JH, Zhang J, Wang H, Koul D, McMurray JS, Fang X, Yung WK, Simnovitch KA (2003): Src family protein-tyrosine kinases alter the function of PTEN to regulate phosphatidylinositol 3-kinase/AKT cascades; J Biol Chem 278(41):40057-40066

Maehama T, Dixon JE (1998): The tumor suppressor, PTEN/MMAC1, dephosphoryltes the lipid second messenger, phosphatidylinositol 3,4,5-triphosphate; J Biol Chem 273(22):13375-13378

Mamdani M, Juurlink D, Lee D, Rochon P, Kopp A, Naglie G, Austin P, Laupacis A, Stukel T (2003): Cyclo-oxygenase-2 inhibitors versus non-selective nonsteroidal anti-inflammatory drugs and congestive heart failure outcomes in elderly patients: a population-based cohort study; The Lancet $\underline{363: 1751-1756}$

Manabe I, Shindo T, Nagai R (2002): Gene expression in Fibroblasts and fibrosis: Involvment in cardiac hypertrophy; Circ Res 91:1103-1113

Mann DL (1999): Mechanisms and models in heart failure: A combinatorial approach; Circulation 100:999-1008

Matsui T, Li L, Wu JC, Cook SA, Nagoshi T, Picard MH, Liao R, Rosenzweig A (2002): Phenotypic spectrum caused by transgenic overexpression of activated Akt in the heart; J Biol Chem 277:22896-22901

McGettigan P, Henry D (2006): Cardiovascular risk and inhibition of cyclooxygenase, a systemic review of the observational studies of selective and nonselective inhibitors of cyclooxygenase 2; JAMA 296:1633-1644

McLenachan JM, Henderson E, Morris KI, Dargie HJ (1987): Ventricular arrhythmias in patients with hypertensive left ventricular hypretrophy; $\mathrm{N}$ Eng J Med 317(13):787-792 
McMullen JR, Shioi T, Zhang L, Tarnavski O, Sherwood MC, Knag PM, Izumo S (2003): Phosphoinositide 3-kinase $(p 110 \alpha)$ plays a critical role for the induction of physiological, but not pathological, cardiac hypertrophy; Proc Natl Acad Sci U S A 100:12355-12360

McMullen JR, Sherwood MC, Tarnavski O, Zhang L, Dorfman AL, Shioi T, Izumo S (2004): Inhibition of mTOR signaling with rapamycin regresses established cardiac hypertrophy induced by pressure overload; Circulation 109:3050-3055

Mesa A, Jessurun C, Hernandez A, Adam K, Brown D, Vaughn WK, Wilansky S (1999): Left ventricular diatolic function in normal human pregnancy; Circulation 99(4):511-517

Messerli FH, Grodzicki T (1992): Hypertension, left ventricular hypertrophy, ventricular arrhythmias and sudden death; Eur Heart J 13 Suppl D:66-69

Michael A, Haq S, Chen X, Hsich E, Cui L, Walters B, Shao Z, Bhattacharay K, Kilter H, Huggins G (2004): Glycogen synthase kinase-3 $\beta$ regulates growth, calcium homeostasis, and diastolic function in the heart; J Biol Chem 279(20):2138321393

Molkentin JD, Lu JR, Antos CL, Markham B, Richardson J, Robbins J, Grant SR, Olson EN (1998): A calcineurin-dependent transcriptional pathway for cardiac hypertrophy; Cell $\underline{\text { 93:215-228 }}$

Morard I, Dumortier J, Spahr L, Hadenaque A, Majno P, Morel P, Mentha G, Giostra E (2007): Conversion to sirolimus-based immunsuppression in maintenance liver transplantation patients; Liver Transpl 13(5):658-664

Morice MC, Serruys PW, Sousa JE, Fajadet J, Hayashi EB, Perin M, Colombo A, Schuler G, Barragan P, Falotico R (2002): A randomized comparison of a sirolimus-eluting stent with a standard stent for coronary revascularization. $\mathrm{N}$ Engl J Med $\underline{346}: 1773-1780$ 
Mosterd A, Cost B, Hoes AW, de Bruijne MC, Deckers JW, Hofman A, Grobbee DE (2001): The prognosis of heart failure in the general population: The Rotterdam Study; Eur Heart J 22(15):1318-1327

Nagoshi T, Matsui T, Aoyama T, Leri A, Anversa P, Li L, Ogawa W, del Monte F Chmapion HC, Rosenzweig A (2005): PI3K rescues the detrimental effects of chronic Akt activation in the heart during ischemia/reperfusion injury; J Clin Invest 115(8):2128-2138

Nakagawa O, Ogawa Y, Itoh H, Suga S, Komatsu Y, Kishimoto I, Nishino K, Yoshimasa T, Nakao K (1995): Rapid transcriptional activation and early mRNA turnover of brain natriuretic peptide in cardiocyte hypertrophy; evidence for brain natriuretic peptide as an "Emergency" cardiac hormone against ventricular overload; J Clin Invest $\underline{96}: 1280-1287$

O'Neill BT, Abel ED (2005): Akt1 in the cardiovascular system: friend or foe?; J Clin Invest 115(8):2059-2064

Pluim BM, Zwinderman AH, van der Laarse A, van der Wall EE (1999): The athlete's heart a meta-analysis of cardiac structure and function; Circulation 100:336-344

Powis G, Bonjouklian R, Berggren MM, Gallegos A, Abraham R, Ashendel C, Zalkow L, Matter WF, Dodge J, Grindey G (1994): Wortmannin, a potent and selective inhibitor of phosphatidylinositol 3-kinase; Cancer Res 54(9):2419-2423

Rothermel BA, McKinsey TA, Vega RB, Nicol RL, Yang J, Antos CL, Shelton JM, Bassel-Duby R, Olson EN, Williams RS (2001): Myocyte-enriched calcineurininteracting protein, MCIP1, inhibits cardiac hyertrophy in vivo; Proc Natl Acad Sci

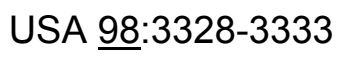

Schlüter KD, Goldberg Y, Taimor G, Schafer M, Piper HM (1998): Role of phosphatidylinositol 3-kinase activation in the hypertrophic growth of adult ventricular cardiomyocytes; Cardiovasc Res 40(1):174-181 
Schmelzle T, Hall MN (2000): TOR, a central cotroller of cell growth; Cell 103(2):253-262

Sekulic A, Hudson CC, Homme JL, Yin P, Otterness DM, Karnitz LM, Abraham RT (2000): A direct link between the phosphoinositide 3-kinase-Akt signaling pathway and the mammalian target of rapamycin in mitogen-stimulated and transformed cells; Cancer Res 60:3504-3513

Selvetella G, Hirsch E, Notte A, Tarone G, Lembo G (2004): Adaptive and maladaptive hypertrophic pathways: points of convergence and divergence; Cardiovasc $\operatorname{Res}$ 63(3):373-378

Shioi T, Kang PM, Douglas PS, Hampe J, Yballe CM, Lawitts J, Cantley LC, Izumo S (2000): The conserved phosphoinositide 3-kinase pathway determine heart size in mice; EMBO 11:2537-2548

Shioi T, McMullen JR, Kang PM, Douglas PS, Obata T, Franke TF, Cantley LC, Izumo S (2002): Akt/protein kinase B promotes organ growth in transgenic mice; Mol Cell Biol 22(8):2799-2809

Shioi T, McMullen JR, Tarnavski O, Converso K, Sherwood MC, Manning WJ, Izumo S (2003): Rapamycin attenuates load-induced cardiac hypertrophy in mice; Circulation 107:1664-1670

Shiojima I, Sato K, Izumiya Y, Schiekofer S, Ito M, Liao R, Colucci WS, Walsh K (2005): Disruption of coordinated cardiac hypertrophy and angiogenesis contributes to the transition to heart failure; J Clin Invest $\underline{115}$ :1208-2118

Silverstein FE, Faich G, Goldstein JL, Simon LS, Pincus T, Whelton A, Makuch R, Eisen G, Agrawal NM, Geis GS (2000): Gastrointestinal toxicity with celecoxib vs nonsteroidal anti-inflammatory drugs for osteoarthritis and rheumatoid arthritis: The CLASS study: A randomized controlled trial. Celecoxib long-term Arthritis safety study; JAMA 284(10):1247-1255 
Solomon DH, Schneeweiss S, Levin R, Avorn J (2004): Relationship between cyclooxygenase-2 specific inhibitors and hypertension; Hypertension 44(2):140-145

Solomon SD, Pfeffer MA, McMurray JJV, Fowler R, Finn P, Levin B, Eagle C, Hawk E Zauber AG, Wittes J (2006): Effect of celecoxib on cardiovascular events and blood pressure in two trials for the prevention of colorectal adenomas; Circulation 114:1028-1035

Stegall MD, Larson TS, Prieto M, Gloor J, Textor S, Nyberg S, Sterioff S, Ishitani M, Griffin M, Velosa J (2003); Kidney transplantation without calcineurin inhibitors using sirolimus; Transplant Proc 35(3 Suppl):125S-127S

Steinbach G, Lynch PM, Philips RK, Wallace MH, Hawk E, Gordon GB, Wakabayashi N, Saunders B, Shen Y, Fujimura T (2000): The effect of celecoxib, a cyclooxygenase-2 inhibitor, in familial adenomatous polyposis; $\mathrm{N}$ Eng $\mathrm{J}$ Med 342(26): 1946-1952

Stephens L, Anderson K, Stokoe D, Erdjument-Bromage H, Painter GF, Holmes AB, Gaffney PR, Reese CB, Tempst P, Hawkins PT (1998): Protein kinase $B$ kinases that mediate phosphatidyinositol 3, 4, 5-triphosphate-dependent activation of protein kinase B; Science $\underline{279}$ :710-714

Stewart MJ, Thomas G (1994): Mitogenesis and protein synthesis: a role for ribosomal protein S6 phosphorylation?; Bioessays 16(11):809-815

Sugden PH, Fuller SJ (1991): Regulation of protin turnover in skeletal and cardiac muscle; Biochem J 273:21-37

Sullivan JM, Vander Zwaag RV, el-Zeky F, Ramanathan KB, Mirvis DM (1993): Left ventricular hypertrophy:effect on survival; J Am Coll Cardiol 22(2): 508-513

Sutton MG, Sharpe N (2000): Left ventrikular remodeling after myocardial infarction: pathophysiology and therapy; Circulation 101(25):2981-1988 
Tanijama Y, Ito M, Sato K, Kuester C, Veit C, Tremp G, Liao R, Colucci WS, Walsh K, Shiojima I (2005): Akt3 overexpression in the heart results in progression from adaptive to maladaptive hypertrophy; Journal of Molecular and Cellular Cardiology $\underline{38}: 375-385$

Vakili BA, Okin PM, Devereux RB (2001): Prognostic implications of left ventricular hypertrophy; Am Heart J 141:334-341

Vanhaesebroeck B, Leevers SJ, Panayotou G, Waterfield MD (1997): Phosphoinositide 3-kinases: a conserved familiy of signal transducers; Trend Biochem Sci 22(7):267-272

Wang J, Mullins CD, Mamdani M, Rublee DA, Shaya FT (2007): New diagnosis of hypertension among celecoxib and nonselective NSAID users: a population-based cohort study; Ann Pharmacother 41(6):937-943

Wang L, Wang X, Proud CG (2000): Activation of mRNA translation in rat cardiac myocytes by insulin involves multiple rapamycin-sensitive steps; Am J Physiol Heart Circ Physiol 287:1056-1068

Whelton A, Lefkowith JL, West CR, Verburg KM (2006): Cardiorenal effects of celecoxib as compared with nonsteroidal anti-inflammatory drugs diclofenac and iboprofen; Kindney Int 70(8):1495-1502

White WB, West CR, Borer JS, Gorelick PB, Lavange L, Pan SX, Weiner E, verburg KM (2007): Risk of cardiovascular events in patients receiving celecoxib: a metaanalysis of randomized clinical trials; Am J Cardiol 99(1):91-98

WHO (1995): Physician Guidelines (for GPs) designed to be translated and distributed worldwide to primary care physicians

Wilkins BJ, Dai Y-S, Bueno OF, Parson SA, Xu J, Plank DM, Jones F, Kimball TR, Molkentin JD (2004): Calcineurin/NFAT coupling participates in pathological, but not physiological, cardiac hypertrophy; Circ Res $\underline{94: 100-118}$ 
Wolfe MM, Lichtenstein DR, Singh G (1999): Gastrointestinal toxicity of nonsteroidal antiinflammatory drugs; N Eng J Med 340(24):1888-1899

Wu T, Leng J, Han C, Demetris AJ (2004): The cyclooxygenase-2 inhibitor celecoxib blocks phosphorylation of Akt and induces apoptosis in human cholangiocarcinoma cell; Mol Cancer Ther $\underline{3}: 299-307$

Yamamoto K, Burnett JC Jr., Jougasaki M, Nishimura RA, Bailey KR, Saito Y, Nakao K, Redfield MM (1996): Superiority of brain natriuretic peptide as a hormonal marker of ventricular systolic and diastolic dysfunction and ventricular hypertrophy; Hypertension 28:988-994

Yamashita K, Kajstura J, Discher DJ, Wasserlauf BJ, Bishopric NH, Anversa P, Webster KA (2001): Reperfusion-activated Akt kinase prevents apoptosis in transgenic mouse hearts overexpressing insulin-like growth factor-1; Circ Res $\underline{88(6)}$ :609614

Yang HM, Kim HS, Park KW, You HJ, Jeon SI, Youn SW, Kim SH, Oh BH, Lee MM, Park YB, Walsh K (2004): Celecoxib, a cyclooxigenase-2 inhibitor, reduces neointimal hyperplasia through inhibition of Akt signaling; Circulation 110:301-308

Zhang J, Ding EL, Song Y (2006): Adverse effects of cyclooxygenase 2 inhibitors on renal and arrhytmia events: a meta-analysis of randamized trials; JAMA 296(13): 1619-1632 


\section{Danksagung}

Herrn Prof. Dr. Gerd Hasenfuß danke ich für das Bereitstellen des Themas, des wissenschaftlichen Umfeldes sowie für die Betreuung der Arbeit.

Dr. Claudius Jacobshagen gilt mein herzlicher Dank für die engagierte und freundliche Betreuung während der gesamten Zeit der gemeinsamen Arbeit.

Für ihren maßgeblichen Anteil an der Durchführung der in-vivo-Versuche danke ich Nils Teucher und Dr. Albrecht Schmidt.

Dank geht an Michael Kothe für die viele Arbeit mit der Isolation der Kaninchenmyozyten und die vielen anderen kleinen und großen Hilfen.

Sandra Ott-Gebauer möchte ich danken für die Einführung in die Labortechniken, die vielen Tipps und Ratschläge bei allen erdenklichen Problemen und dafür, dass ich mich im Labor immer wohl gefühlt habe.

Dr. Harald Kögler und Dr. Tim Seidler danke ich für die vielen konstruktiven Antworten auf die kleinen Fragen zwischendurch.

Allen Mitarbeitern der Abteilung möchte ich für die nette Zusammenarbeit danken, besonders Jessica Spitallieri und Cornelia Grebe. 


\section{Lebenslauf}

Am 4. April 1982 wurde ich, Meike Grüber, als erstes von fünf Kindern von Jörg Grüber, Unfallchirurg, und Ingrid Grüber geb. Drews, Erzieherin, in Visp in der Schweiz geboren.

In den Jahren 1988 bis 1992 besuchte ich die Grundschule Windmühlenweg in Hamburg. Im Jahre 1992 erfolgte der Übergang auf das humanistische Gymnasium Christianeum in Hamburg, welches ich 2001 mit dem Erhalt der allgemeinen Hochschulreife abschloss.

Zum Wintersemester 2001 begann ich mein Medizinstudium an der Universität Hamburg. Im Rahmen eines Modellstudienganges absolvierte ich hier die ersten sechs Semester und schloss diese mit einer Äquivalenzprüfung, dem Physikum und Teilen des 1. Staatsexamens nach alter Approbationsordnung entsprechend, ab. Zum Wintersemester 2004 wechselte ich an die Georg-August-Universität in Göttingen, um hier mein Medizinstudium fortzusetzen.

Seit Oktober 2004 habe ich im Rahmen meiner Doktorarbeit in der Abteilung für molekulare Kardiologie bei Prof. Hasenfuß mitgearbeitet.

Im Rahmen des Praktischen Jahres des Medizinstudiums arbeitete ich von Februar bis Juni 2007 in der Chirurgie im Spitalzentrum Oberwallis in der Schweiz, im Juni bis Oktober 2007 in der Abteilung für Innere Medizin im Klinikum in Oldenburg und von Oktober bis Januar in der Gynäkologie im Klinikum in Oldenburg.

Seit dem 01.08.2009 arbeite ich als Assistenzärztin in der Abeilung für Gynäkologie und Geburtshilfe im Albertinenkrankenhaus in Hamburg. 